\title{
Research Paper: \\ Effect of Resistance Exercise and Liposomal Vitamin C on Some Factors of Mito- chondrial Dynamics and Biogenesis
}

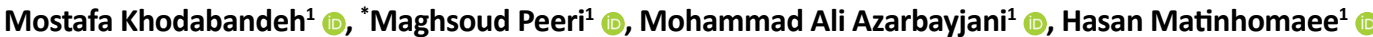

1. Department of Sports Physiology, Faculty of Physical Education and Sports Sciences, Central Tehran Branch, Islamic Azad University, Tehran, Iran.

\begin{tabular}{|c|c|}
\hline $\begin{array}{l}\text { Use yourd device to scan } \\
\text { and read the article online }\end{array}$ & Crtation: Khodabandeh M, Peeri M, Azarbayjani MA, Matinhomaee H. [Effect of Resistance Exercise and Liposomal Vitamin \\
\hline atsing & $\begin{array}{l}\text { C on Some Factors of Mitochondrial Dynamics and Biogenesis (Persian)]. Complementary Medicine Journal. 2021; 11(1):82-97. } \\
\text { https://doi.org/10.32598/cmja.11.1.1057.1 }\end{array}$ \\
\hline aingrip & dol'https://doi.org/10.32598/cmja.11.1.1057.1 \\
\hline
\end{tabular}

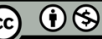

Article Info:

Received: 09 Jan 2021 Accepted: 28 Feb 2021 Available Online: 01 Apr 2021

Keywords:

Reactive oxygen specific, PGC-1 $\alpha$, Mitofusin 1, Resistance exercise, Aging, Vitamin C

\section{A B STRACT}

Objective Aging is associated with some changes in the liver function including increased collagen deposition and decreased mitochondrial function. This study aims to evaluate the effect of resistance exercise and vitamin $C$ intake on the expression of Peroxisome Proliferator-Activated Receptor- $\Gamma$ Coactivator-1 $\alpha$ (PGC-1 $\alpha$ ) and Mitofusin 1 (MFn1) genes and collagen deposition in older rats.

Methods This is an experimental study conducted on 25 male Wistar rats aged 24 weeks and weighted 280-320 g. They were randomly divided into five groups of young control, older exercise, older vitamin C, older exercise + vitamin C, and older control. In the supplementation groups, rats were given liposomal vitamin C (100 mg/kg per body weight) by gavage daily. One-way ANOVA was used to examine the difference between the groups and Tukey's post hoc test was used to determine the location of group differences. For all analyses, the significance level was set at 0.05 .

Results Aging significantly reduced the expression of PGC-1 $\alpha$ and MFn1 and increased collagen deposition in the liver tissue of rats $(P=0.001)$. In the older exercise + vitamin $C$ group, a significant increase in PGC-1 $\alpha$ expression was observed compared to the older control group $(P=0.001)$, but there was no significant changes in MFn1 expression. A significant decrease in collagen deposition was reported in the older exercise, older vitamin C, and older exercise + vitamin C groups compared to the older control group $(\mathrm{P}=0.001)$.

Conclusion Resistance exercise combined with vitamin C intake reduces collagen deposition in liver tissue and increases PGC-1 $\alpha$ expression in older rats.

\section{Extended Abstract}

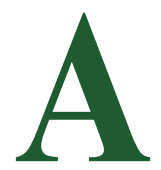

\section{Introduction}

ging is associated with increased collagen deposition and decreased hepatic mitochondrial biogenesis $[1,2]$. Increase in important regulators of Peroxisome Proliferator-Activated Receptor- $\gamma$ Coactivator- $1 \alpha$ (PGC-1 $\alpha$ ) plays an im- portant role in inhibiting ROS and mitochondrial biogenesis [3]. Aging can also affect the dynamics of mitochondria [4]. Mitochondrial dynamics involves the fission and fusion process. The most important fusion protein is MFn1 [5]. Some studies have shown that a decrease in MFn1 leads to an increase in collagen deposition [6]. Studies have shown that exercise can increase mitochondrial biogenesis [7]. Some studies have shown that resistance exercise causes collagen deposition in the heart [8]. On the other hand, studies have shown that vitamin $\mathrm{C}$ is effective in increasing collagen pro-

\section{${ }^{*}$ Corresponding Author:}

Maghsoud Peeri, PhD.

Address: Department of Sports Physiology, Faculty of Physical Education and Sports Sciences, Central Tehran Branch, Islamic Azad University, Tehran, Iran. Tel: +98 (21) 22481649

E-mail: mpeeri@iauctb.ac.ir 


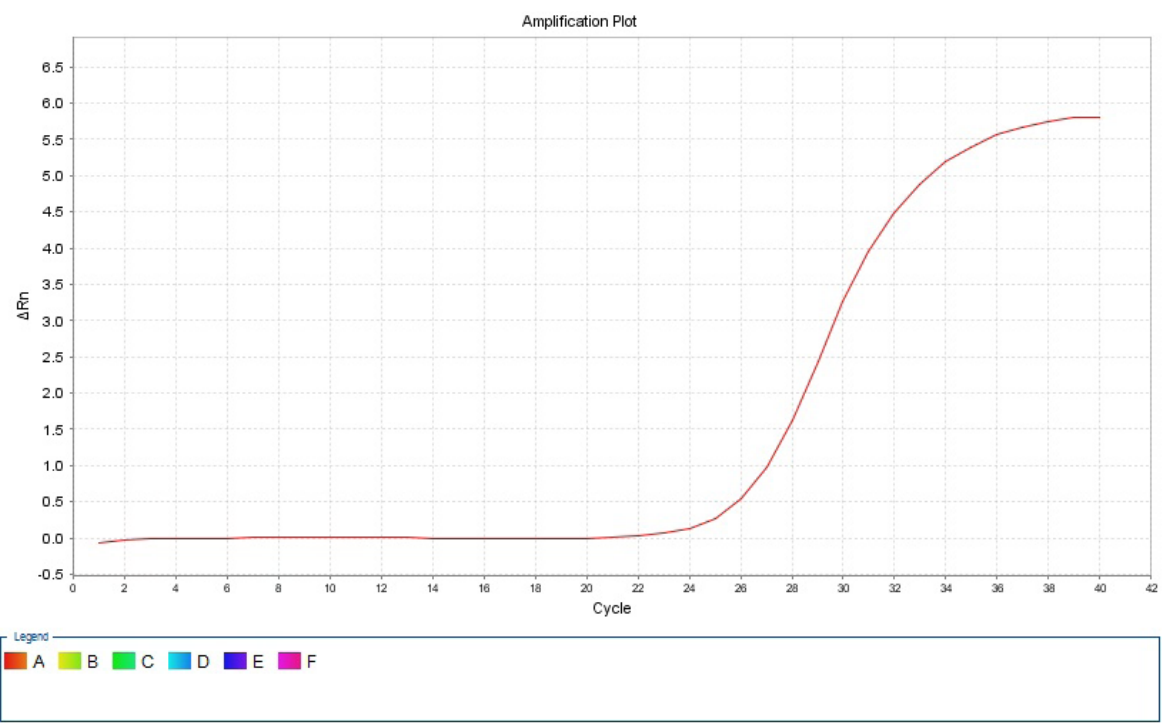

Figure 1. Amplification curve of PGC-1a Complementary Medicine Journal
Arak University of Medical Sciences

duction [9]. Decreased mitochondrial biogenesis is one of the main factors in increasing the aging process and its related damage to body tissues, especially liver tissue. It can be controled by various methods such as exercise and consumption of antioxidants. The aim of this study was to evaluate the effect of exercise and vitamin C intake on PGC-1 $\alpha$, MFn1 and collagen deposition in older rats.

\section{Materials and Methods}

This is an experimental study conducted on 25 male Wistar rats with 24 weeks of age and 280-320 g of weight, randomly divided into 5 groups of 5 including young control, older exercise, older vitamin C, older exercise + vitamin C, and older control. In the exercise groups, 20 minutes of resistance exercise with ladders and weights were performed for 8 weeks, three days a week, each day for $20 \mathrm{~min}$. In the groups receiving supplementation, daily liposomal vitamin $\mathrm{C}$ was administered by gavage per $\mathrm{kg}$ / body weight.

Shapiro-Wilk test was used to evaluate the normality of data distribution. One-way ANOVA was used to examine the differences between groups, and Tukey's post hoc test was used to determine the location of group differences. All analyses were performed in SPSS v. 22 software considering a significance the level of $\mathrm{P}<0.05$.

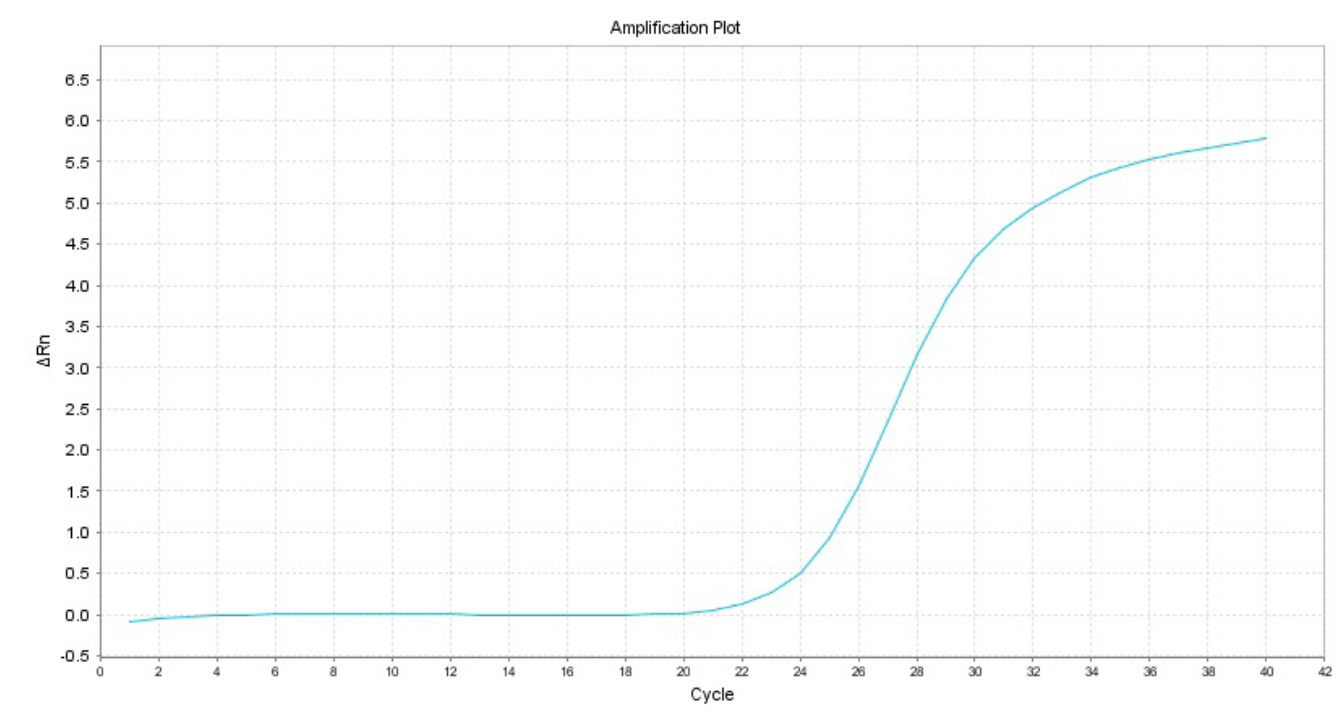

A $\square$ B $\square$ C $\square$ D $\square$ E $\square$

Figure 2. Amplification curve of MFn1 


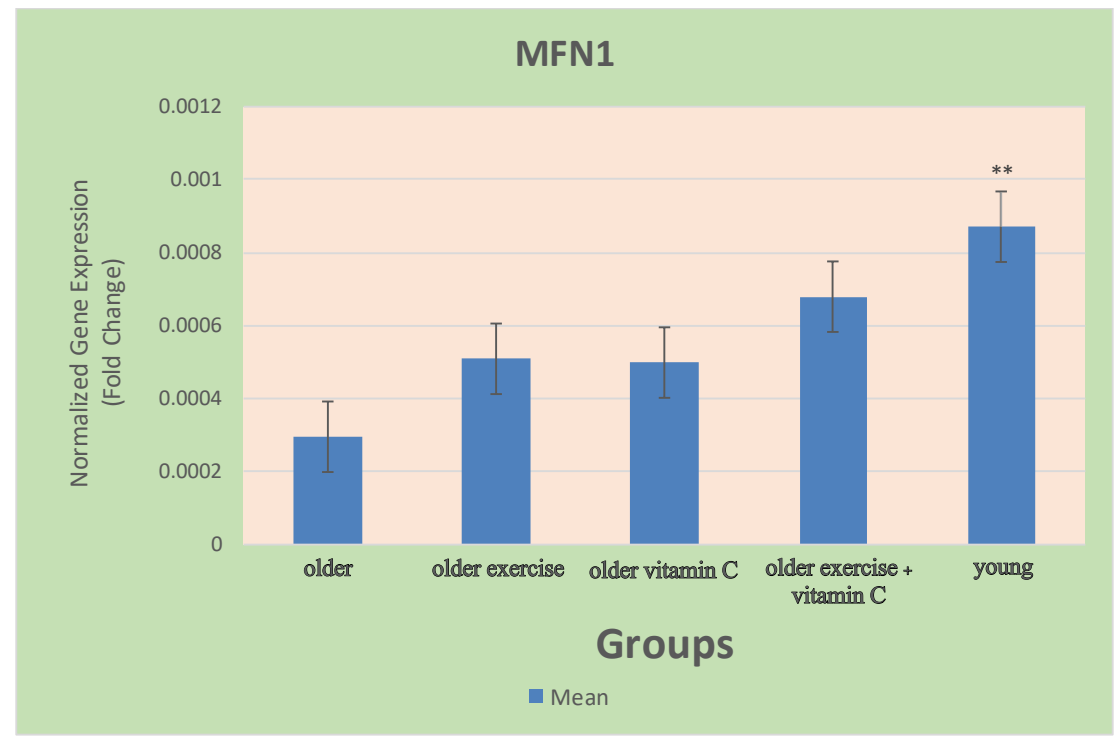

Figure 3. Expression of PGC-1 $\alpha$ in different study groups

${ }^{* *}$ Significant compared to the older control group $(\mathrm{P}<0.05)$.

\section{Results}

ANOVA results showed a significant difference between the groups in terms of PGC- $1 \alpha$ expression $(\mathrm{P}=0.001)$. The results of post hoc test showed that the difference was between the older and young control groups where the level of PGC-1 $\alpha$ was higher in the young control group $(\mathrm{P}=0.001)$, and also between the older control and older exercise + vitamin $\mathrm{C}$ groups where the older exercise + vitamin $\mathrm{C}$ group had a higher level of PGC- $1 \alpha$ compared to the older control group $(\mathrm{P}=0.001)$. There was no significant difference between other groups.

ANOVA results also showed a significant difference between the groups in terms of MFn1 $(\mathrm{P}=0.001)$. The results of post hoc test showed that the difference was between the older and young control groups where the level of MFn1 was higher in the young control group $(\mathrm{P}=0.001)$. There was no significant difference between other groups.

ANOVA results also showed a significant difference between the groups in terms of collagen deposition $(\mathrm{P}=0.001)$. The results of post hoc test showed that that the young control, older exercise, older vitamin $\mathrm{C}$, and older exercise + vitamin $\mathrm{C}$ had significantly different collagen deposition compared to the older control group $(\mathrm{P}=0.001)$. The difference was also significant between the older exercise + vita$\min \mathrm{C}$ and the older vitamin c groups, between the young control and the older vitamin c groups, and between the older exercise + vitamin $\mathrm{C}$ and the young control groups $(\mathrm{P}=0.001)$ (Figures 1, 2, 3, 4, 5 \& 6).

\section{Conclusion}

The purpose of this study was to evaluate the effect of exercise and vitamin $\mathrm{C}$ intake on collagen deposition and expression of PGC-1 $\alpha$ and MFn1 in liver tissue of older rats. Our results showed that aging significantly reduced PGC-1 $\alpha$ and MFn1 levels. Resistance exercise combined with vitamin $\mathrm{C}$ consumption significantly increased PGC$1 \alpha$ level, but MFn1 was not increased significantly. Resistance training and vitamin $\mathrm{C}$ consumption alone had no significant effect on PGC-1 $\alpha$ and MFn1 in the older rats. Resistance exercise and vitamin $\mathrm{C}$ intake alone were effective in reducing collagen deposition, but their combination led to better results. Wenz et al. reported that an increase in PGC- $1 \alpha$ leads to a decrease in muscle collagen deposition and a decrease in fibrosis [10]. Since resistance exercise combined with vitamin $\mathrm{C}$ increased PGC-1 $\alpha$, this possibility reduced calcium deposition.

There are few studies on the effects of exercise on mitochondrial dynamics, and the exact mechanism of controlling mitochondrial regeneration is unclear. Studies have shown that PGC-1 $\alpha$ is involved in adaptation and response to exercise. Regulation of mitochondrial dynamics is influenced by intracellular metabolic regulators. PGC-1 $\alpha$ is one of the most important regulators of energy metabolism and mitochondrial biogenesis, which is involved in mitochondrial regeneration by affecting fusion and fission. In this regard, some studies have shown that acute exercise increases the expression of mRNA and MFn1 protein levels in skel- 


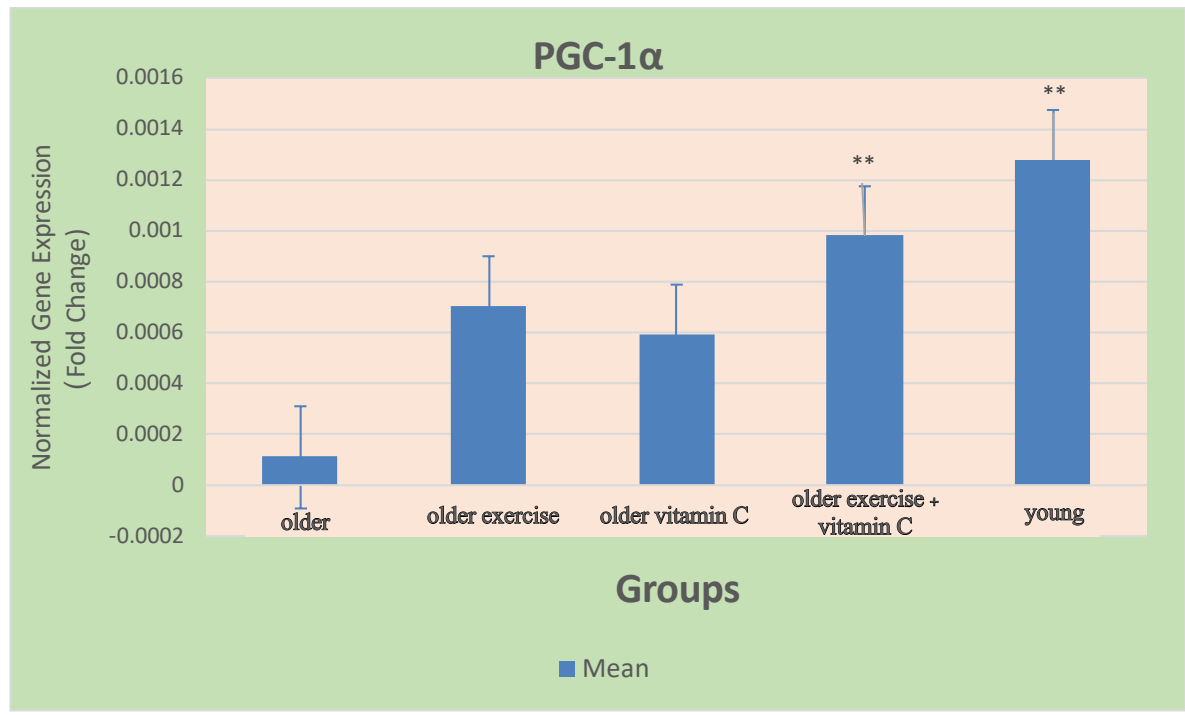

Figure 4. Expression of MFn1 in different study groups.

Complementary Medicine Journal

${ }^{* *}$ Significant compared to the older control group $(\mathrm{P}<0.05)$

etal muscle, which is in line with the increase in PGC- $1 \alpha$

[11]. Laboratory studies have shown that MFn1 expression is significantly reduced in muscle cells lacking PGC- $1 \alpha$ [12], while increased expression of PGC- $1 \alpha$ stimulates the expression of mRNA and MFn1 protein in cultured muscle cells [13]. Moreover, overexpression of PGC-1 $\alpha$ and exercise-induced mitochondrial biogenesis are sensitive to cellular redox. Inhibition of Reactive Oxygen Species reduces the expression of PGC- $1 \alpha$ and the expression of mitochondrial biogenesis genes controlled by PGC-1 $\alpha$ [14].
Resistance training along with vitamin $\mathrm{C}$ consumption in older rats reduces collagen deposition in liver tissue and increases PGC-1 $\alpha$ expression.

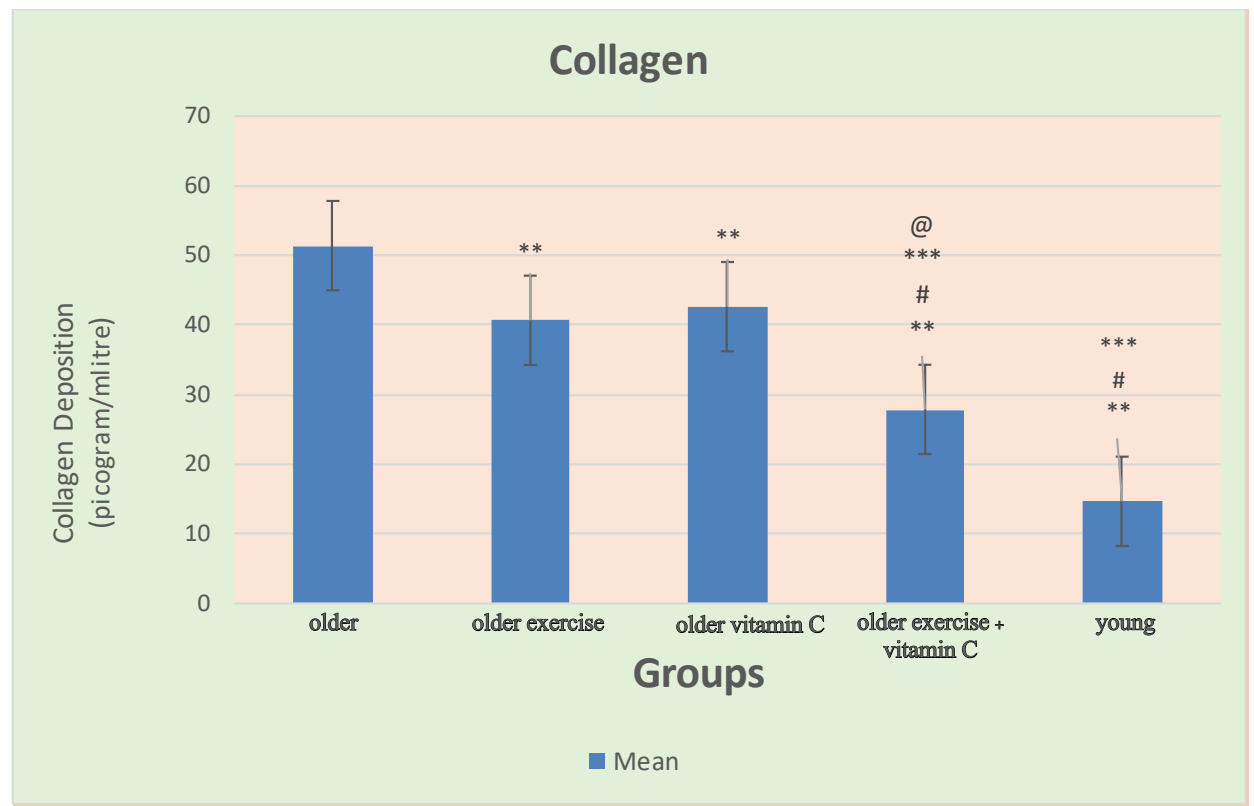

Figure 5. Collagen deposition in different study groups

Complementary Medicine Journal
Arak University of Medical Sciences

${ }^{* *}$ Significant compared to the older control group $(\mathrm{P}<0.05)$; ${ }^{\#}$ Significant compared to the older + exercise group $(\mathrm{P}<0.05)$; ${ }^{* * *}$ Significant compared to the older + vitamin $\mathrm{C}$ group $(\mathrm{P}<0.05) ;{ }^{\circledR}$ Significant compared to the older + exercise + vitamin $\mathrm{C}$ group $(\mathrm{P}<0.05)$. 

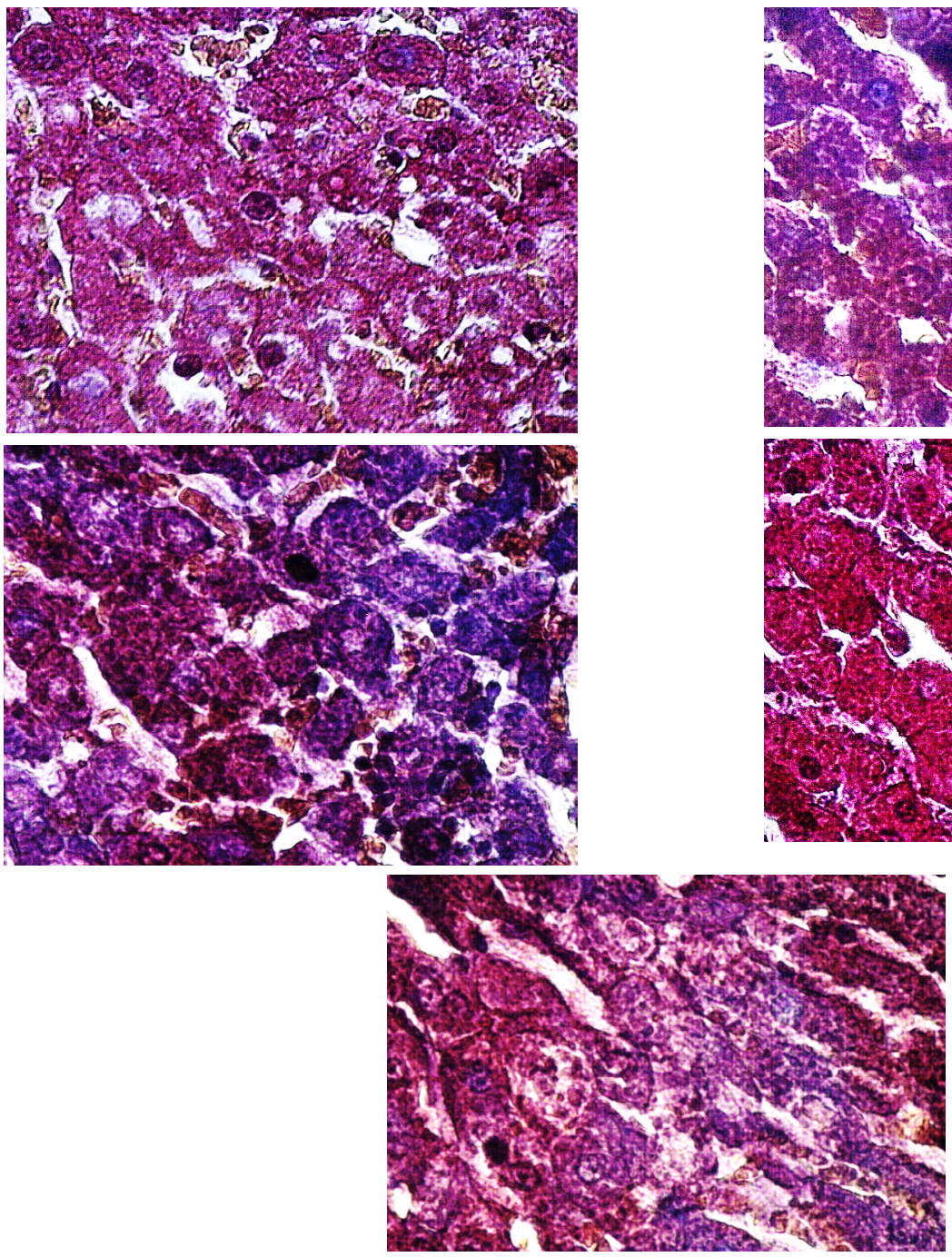

Figure 6. Collagen deposition in different study groups

\section{Ethical Considerations}

Compliance with ethical guidelines

This study was approved by the Ethics Committee of Sport Sciences Research Institute of Iran (Code: IR.SSRI. REC.1399.775). All ethical principles are considered in this article. The participants were informed about the purpose of the research and its implementation stages. They were also assured about the confidentiality of their information and were free to leave the study whenever they wished, and if desired, the research results would be available to them.

Funding

The paper was extracted from $\mathrm{PhD}$. Dissertation of the Mostafa Khodabandeh, Department of Sports Physiology, Faculty of Physical Education and Sports Sciences, Islamic Azad University, Central Tehran Branch.
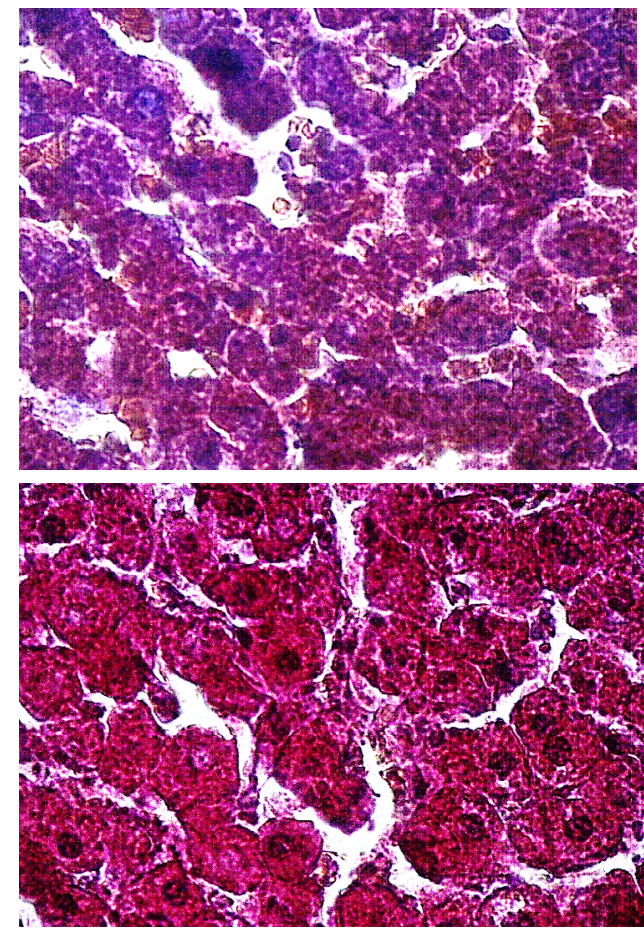

敞 Complementary Medicine Journal
Arak University of Medical Sciences

Authors' contributions

Conceptualization, methodology, writing - review \& editing: All authors; Investigation, writing - original draft, funding acquisition: Mostafa Khodabandeh, Maghsoud Peeri; Resources: Maghsoud Peeri,Hasan Matinhomaee.

Conflicts of interest

The authors declar eno conflict of interest 


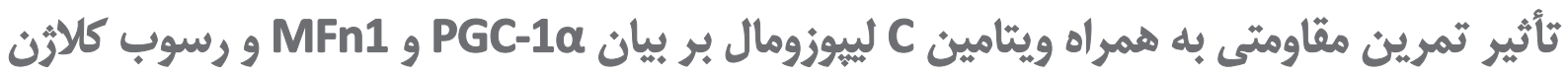

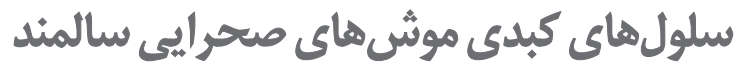

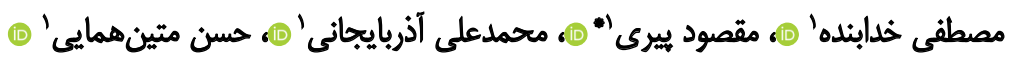
1. كروه فيزيولورى ورزشى، دانشكده تربيت بدنى و علوم ورزشى، واحد تهران مركزى، دانشعاه آزاد اسلامى، تهران، ايران.

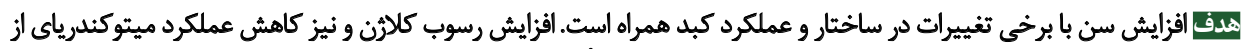

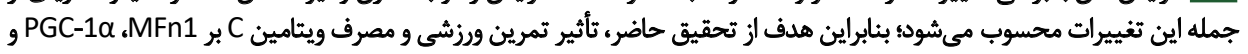

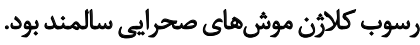

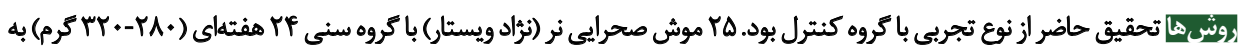

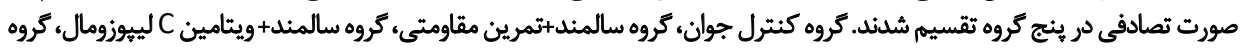

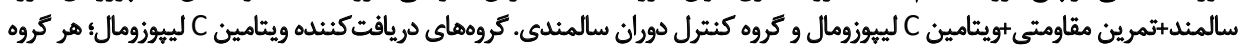

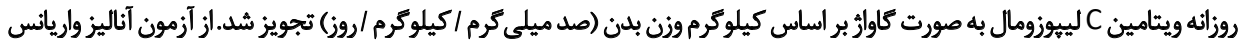

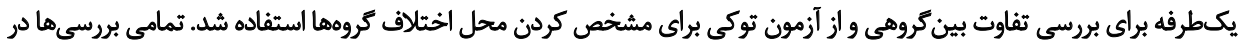

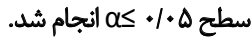

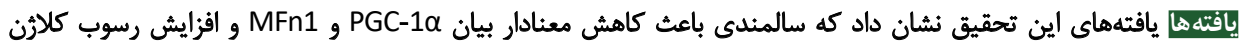

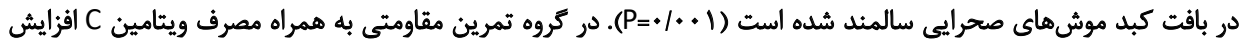

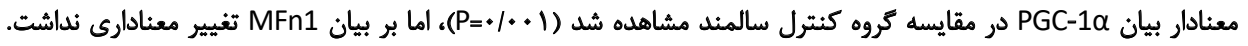

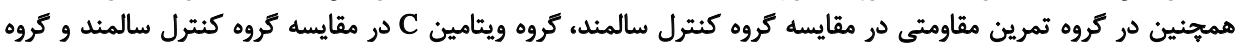

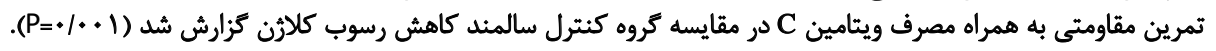

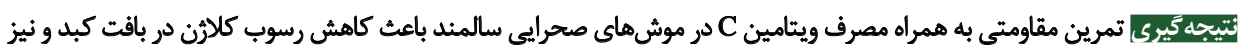

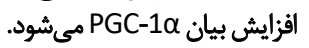

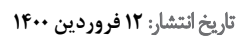

كليدوازمها:

PGC-10، MFn1،

تمرين مقاومتى، المنا، C سالمندى، ويتامين مقاومتين C

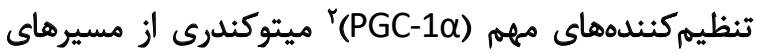

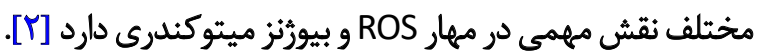

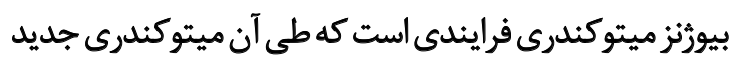

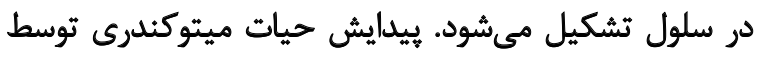

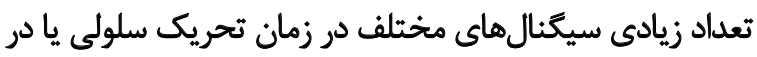

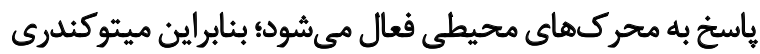

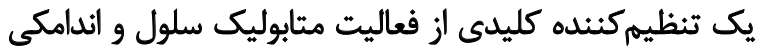

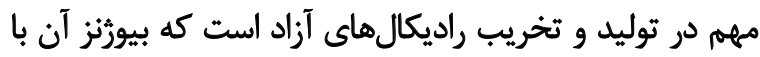

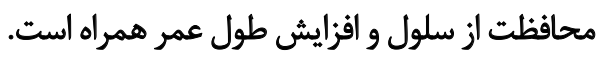

مقدمه

يكى از فرضيات اصلى كه با تسريع در روند سالمندى همراه

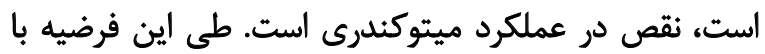

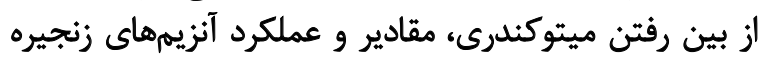

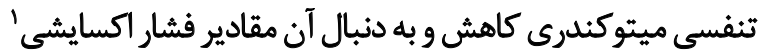

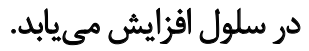

اين فرايند سبب تخريب سلولى و كاهش طول عمر به دئ دنبال

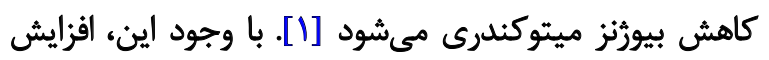

2. Peroxisome proliferator

1. Species Oxygen Reactive (ROS)

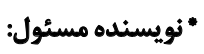

دكتر مقصود بييرى نوئدول

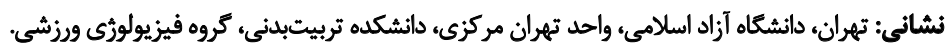

تلفن:

بست الكترونيكى: mpeeri@iauctb.ac.ir 
در كبد جرب غيرالكلى در اثر هوازى اشاره كردهاند [ه|]]. از سوى ديگر، تزارش شده كه مصرف ويتامين C، استرس

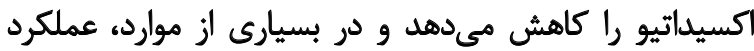

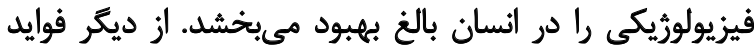

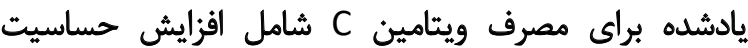

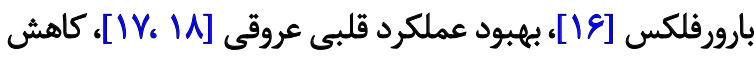

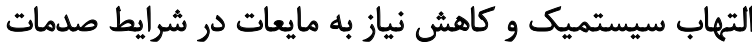

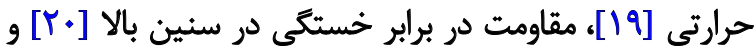

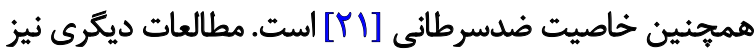

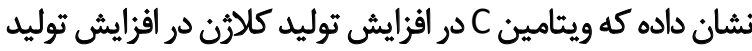

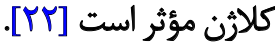

در هر حال، كاهش بيوزثنز ميتوكندرى يكى از عوامل اصلى در بري

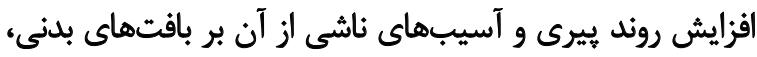

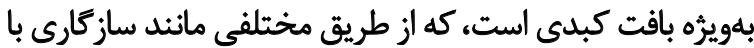

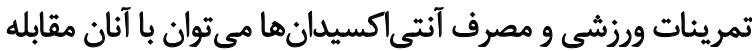

مطالعات محدودى به بررسى نقش ويتامين C، بهويرٔه فرم

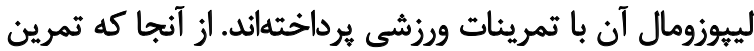

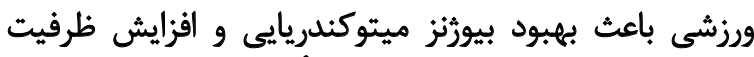

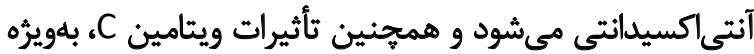

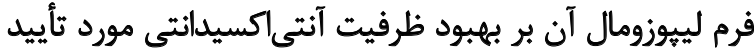

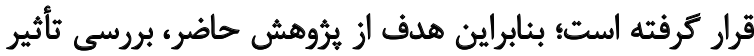

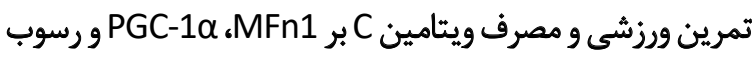
كلارن موشهاي صحرايى سالمند است.

\section{مواد و روش ها}

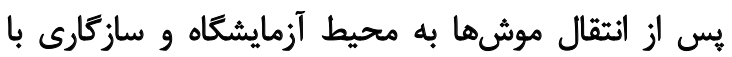

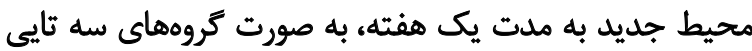

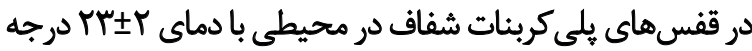

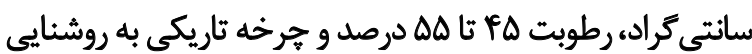

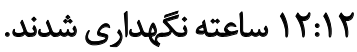

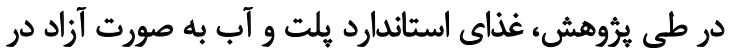

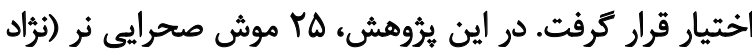

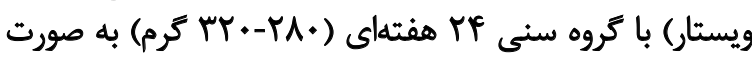

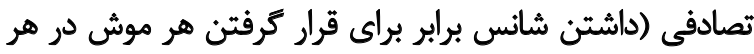

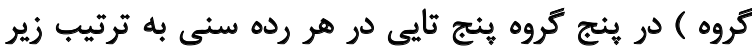
تقسيم شده و مورد مطالعه قرار كرفتند:

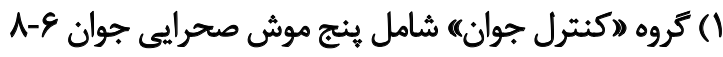

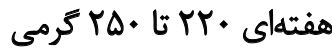
T) كروه (اسالمند+تمرين مقاومتى) شامل ينج موش صحرايى

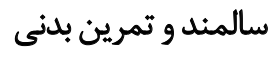

يكى از مهمترين كواكتيويتورهاى رونويسى است

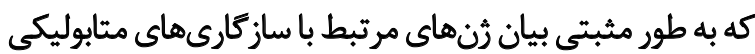

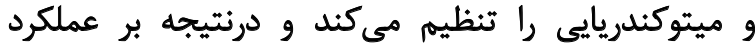
ميتوكندرى، ظرفيت توليد ATP ونيز توليد ROS تأثير مي كئدارد

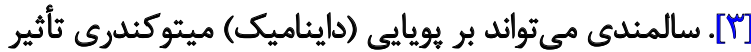

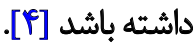

يويايى ميتوكندريايى شامل فرايند شكاف و همجرشى است

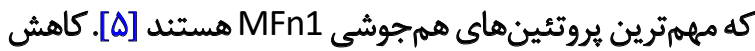

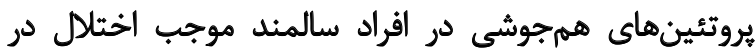

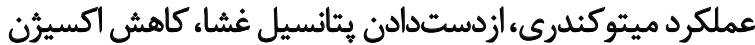

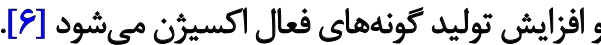
عدم تعادل در يروتئينهاى همرجوشى MFn1 شكافت، باعث

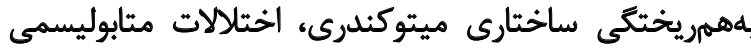

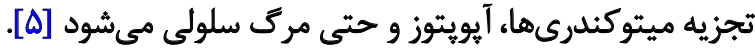

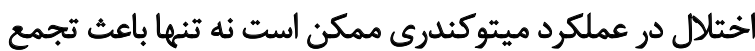

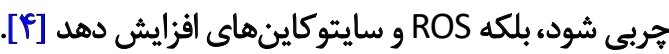
علاوه بر اين، افزايش سن با افزايش رسوب كلارثن نيز همراه

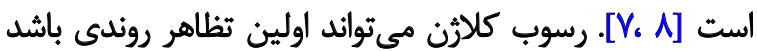

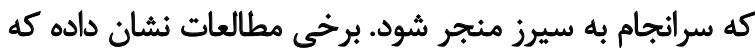

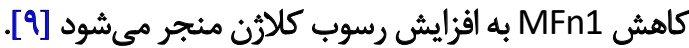
مطالعات نشان داده كه بهبود سبك زندكى، افزايش تحرى

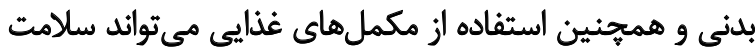

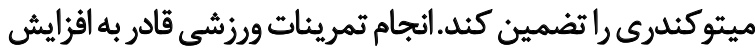

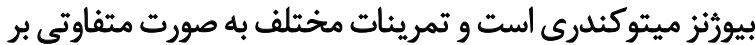

ميتوكندرى تأثيركذار باشند [• [1].

انجام تمرينات ورزشى با افزايش مقادير آنزيمهاى

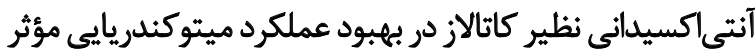

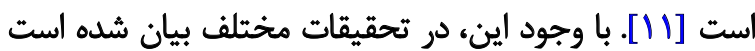

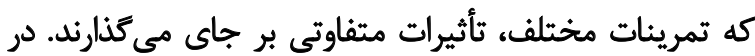

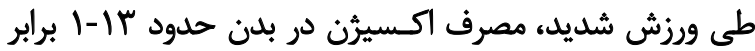

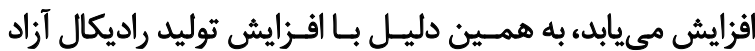

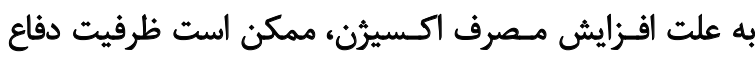

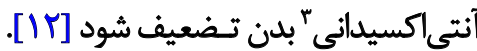

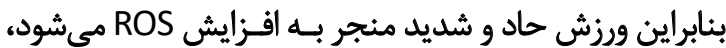

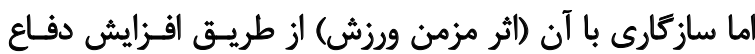

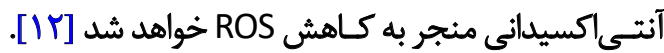
يكى از ياسخ هايى كه بدن به كاهش ROS مى دهد، افزايش

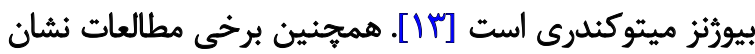

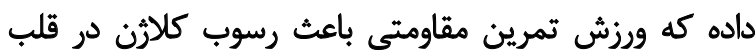

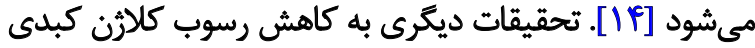

3. Capacity Defense Antioxidant 


\begin{tabular}{|c|c|}
\hline توالي هيرايمر & متغيرها \\
\hline pGC1 R & TCT CTG TGG GTT TGG TGT GA \\
\hline pGC1 F & TCA GCG GTC TTA GCA CCT A \\
\hline Mfn1 R & ATC GGA TCT TTT TTG TTT CAG C \\
\hline Mfn1 F & СTC CTG TAA TCT TGC CTG \\
\hline
\end{tabular}

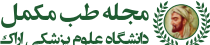

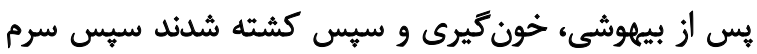

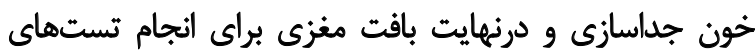

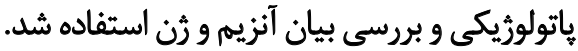

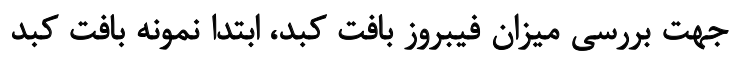

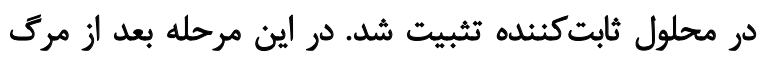

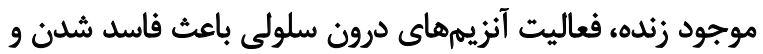

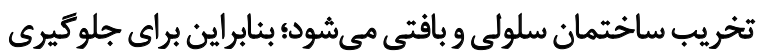

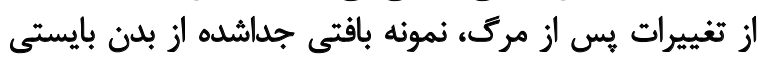

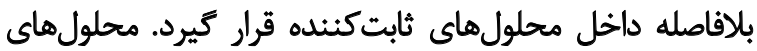

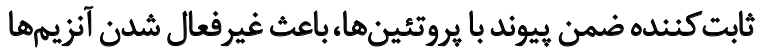

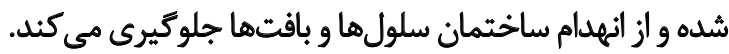

سيس به ترتيب مراحل آبغيرى با الكل، شفافسازى با كزيلل،

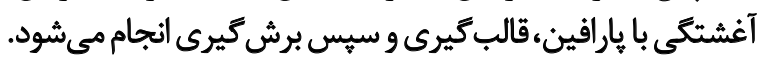

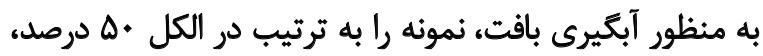

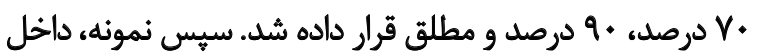

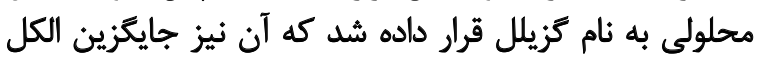

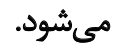

r) كروه "اسالمند+ويتامين C لييوزومال) شامل ينج موش صحرايى سالمند و ويتامين C لييوزومال

(f) كروه "اسالمند+تمرين مقاومتى +ويتامين C لييوزومال)

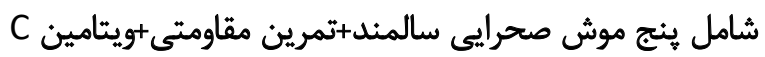
لينيوزومال شامل ينج مون ه) گروه هكنترل دوران سالمندى) شامل ينج موش صحرايى

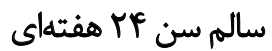

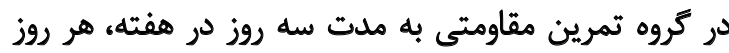

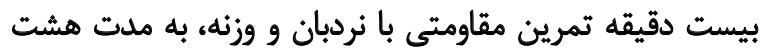

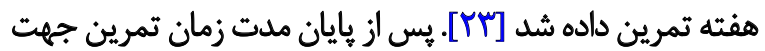

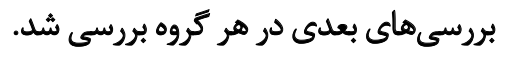
در كروهاه دريافت كننده ويتامين C لييوزومال، در هر كروه

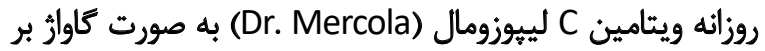
اساس كيلوكرم وزن بدن (صد ميلى كرم / كيلوكرم / روز) تجويز

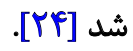
در هر كروه، وزن در ابتدا و انتهاى مطالعه بررسى شد. موشها

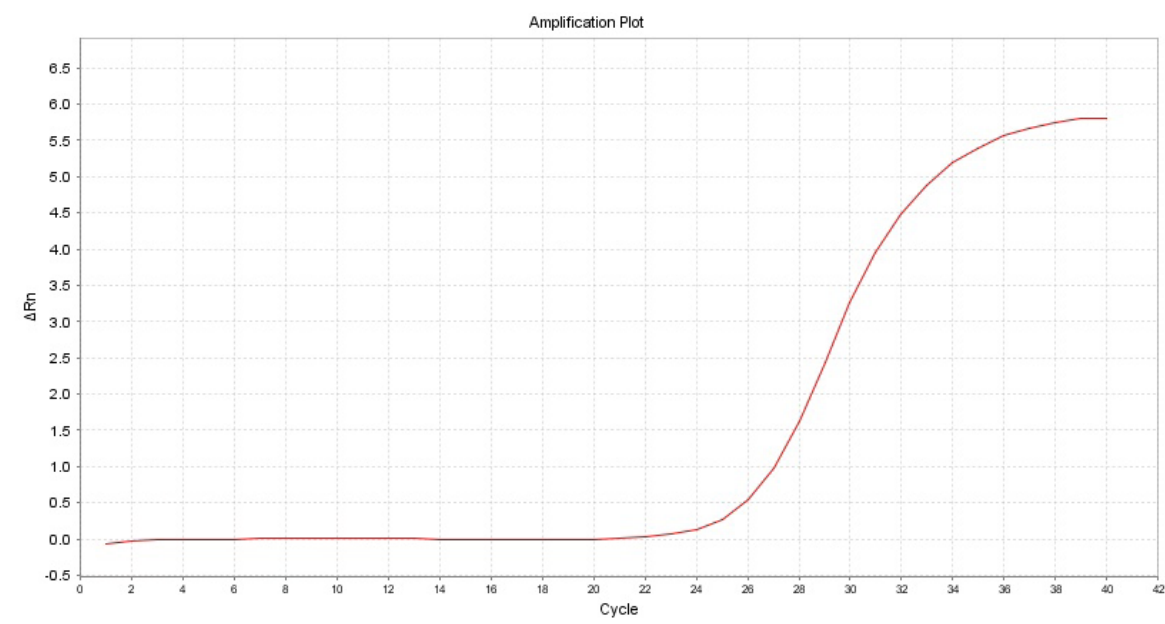




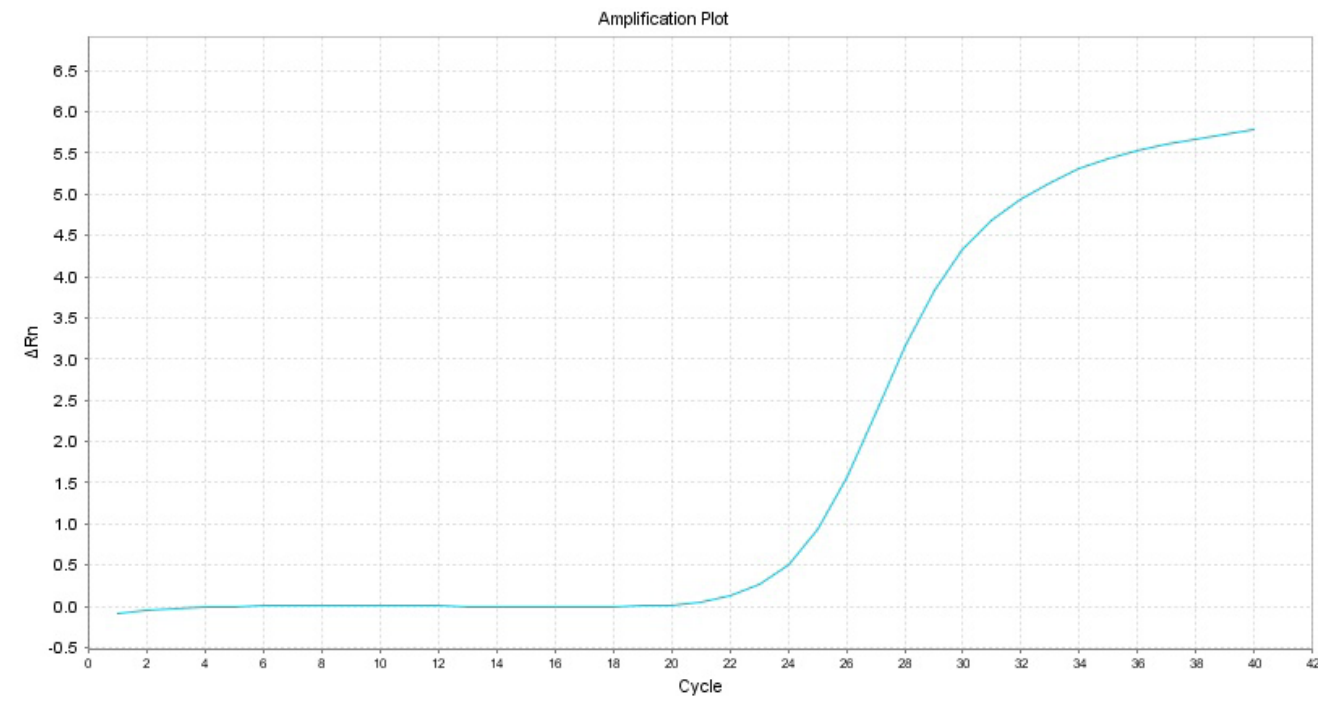

در مرحله آغشتكى، نمونه را در داخل ثارافين مذاب قرار

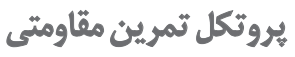

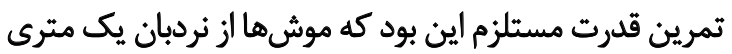

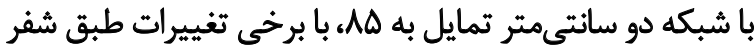

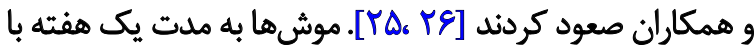

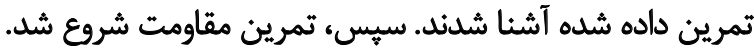

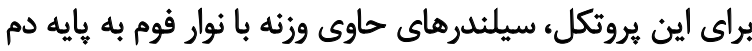

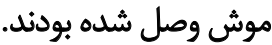

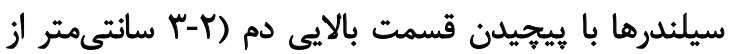

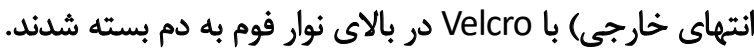

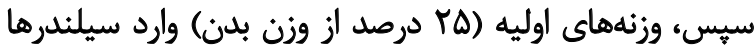

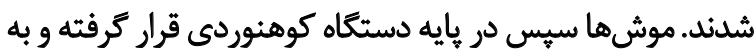

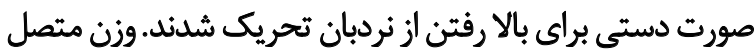

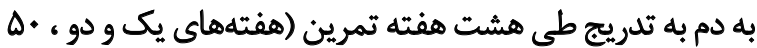

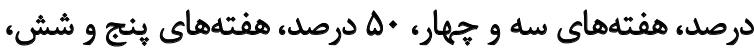

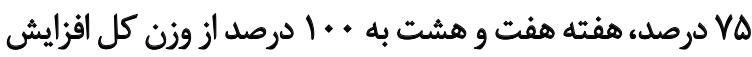

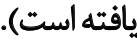

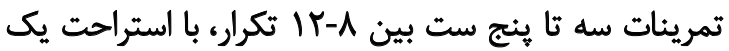

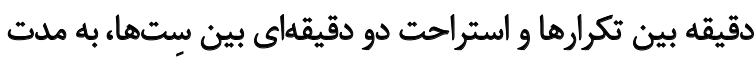

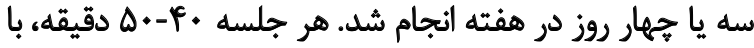

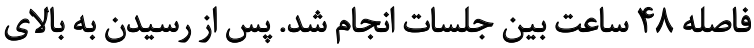

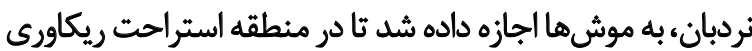

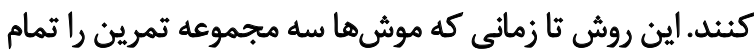
كردند يا آنها نتوانستند طول كلي كل كوش نردبان را صعود كنند، تكرار

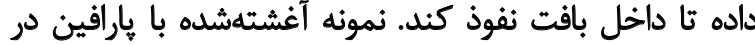

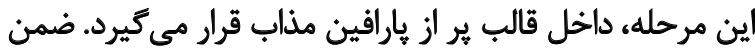

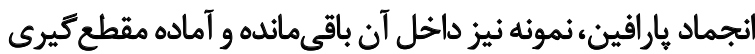

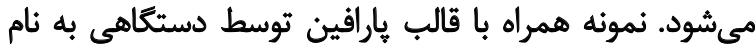
ميكروتوم به ضخامت ينج تا ده ميكرون برش داده باد مي تشود.

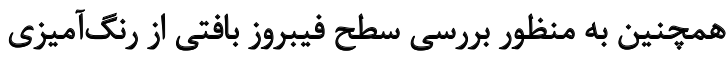

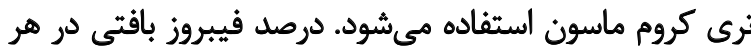

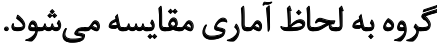

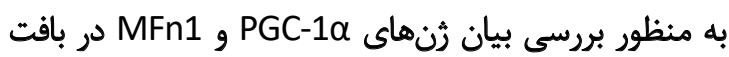

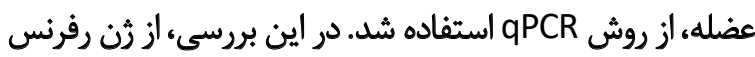

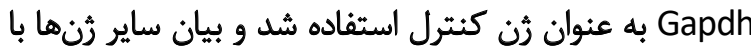

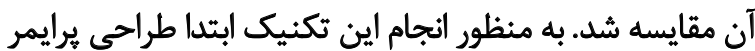

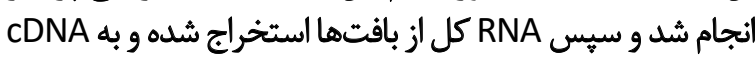

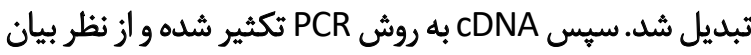

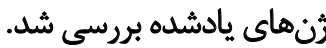
استخراج RNA به روش دستى با استفاده از ماده ترايزول

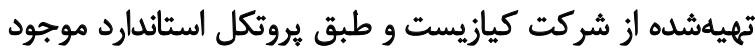

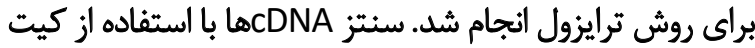

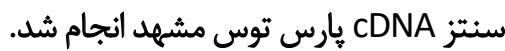

شماره كاتالوك يا Cat no.: A101161. همجنين طراحى برائ

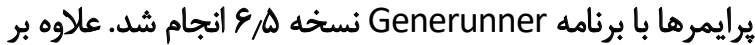

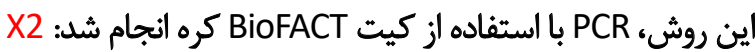
,neerG RBYS gnidulcni) xiM retsaM RCP emiT-laeR h04-583QD .on tac .(XOR hgiH 


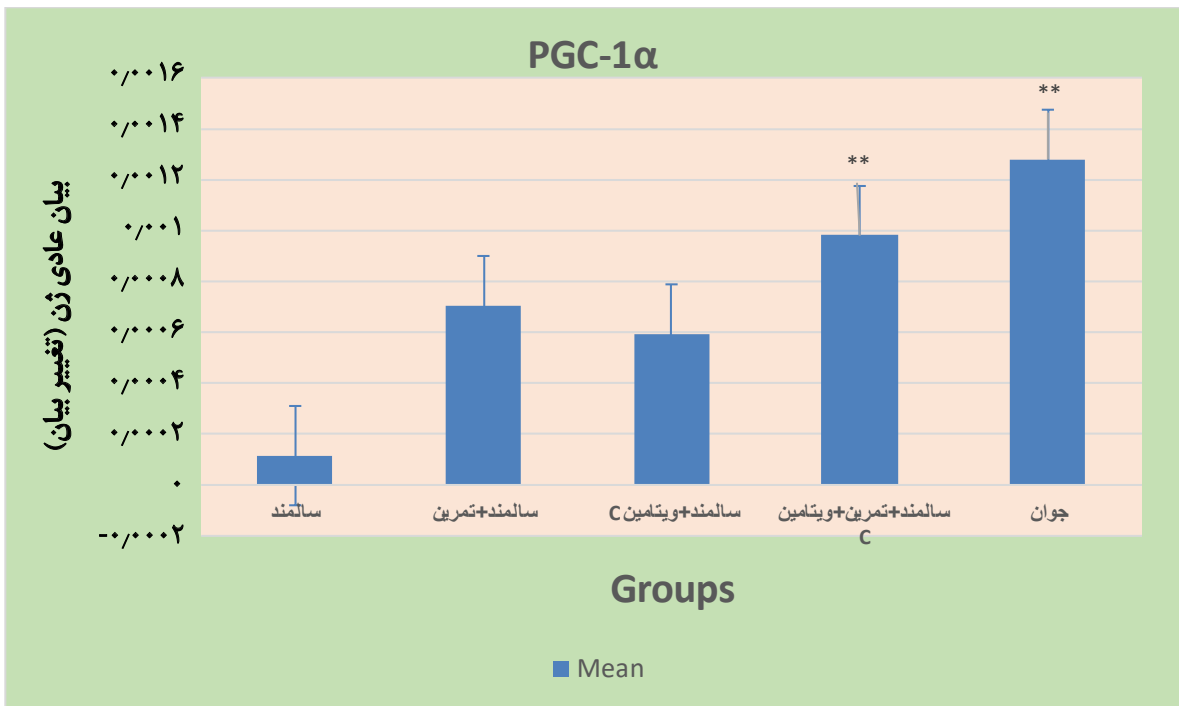

(1)

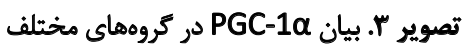

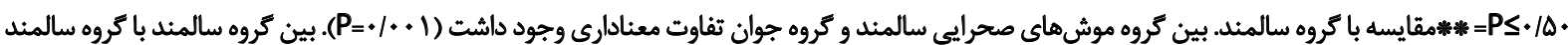

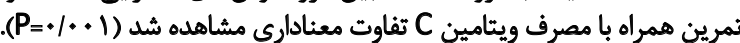

هودر آلن دويتاسي رادر آن ريخته و مجدداً روى اجاق كذاشته، به

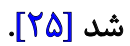
هم زديم تأ كاملا حل شود.

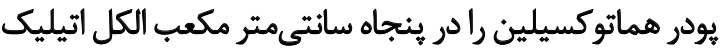

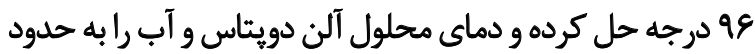

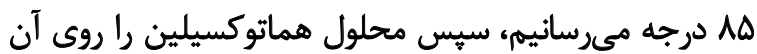

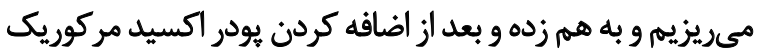

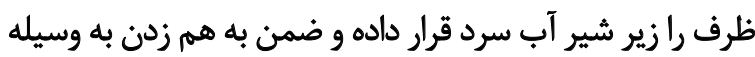

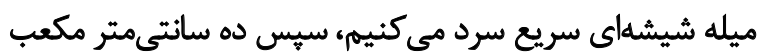

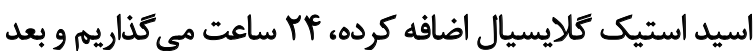

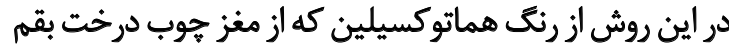

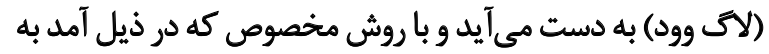

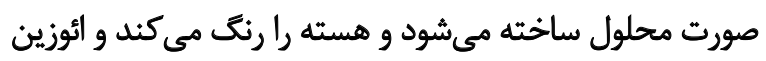

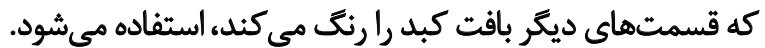

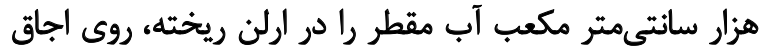

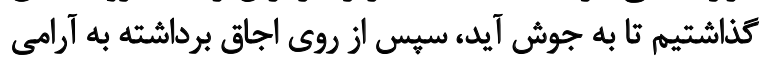

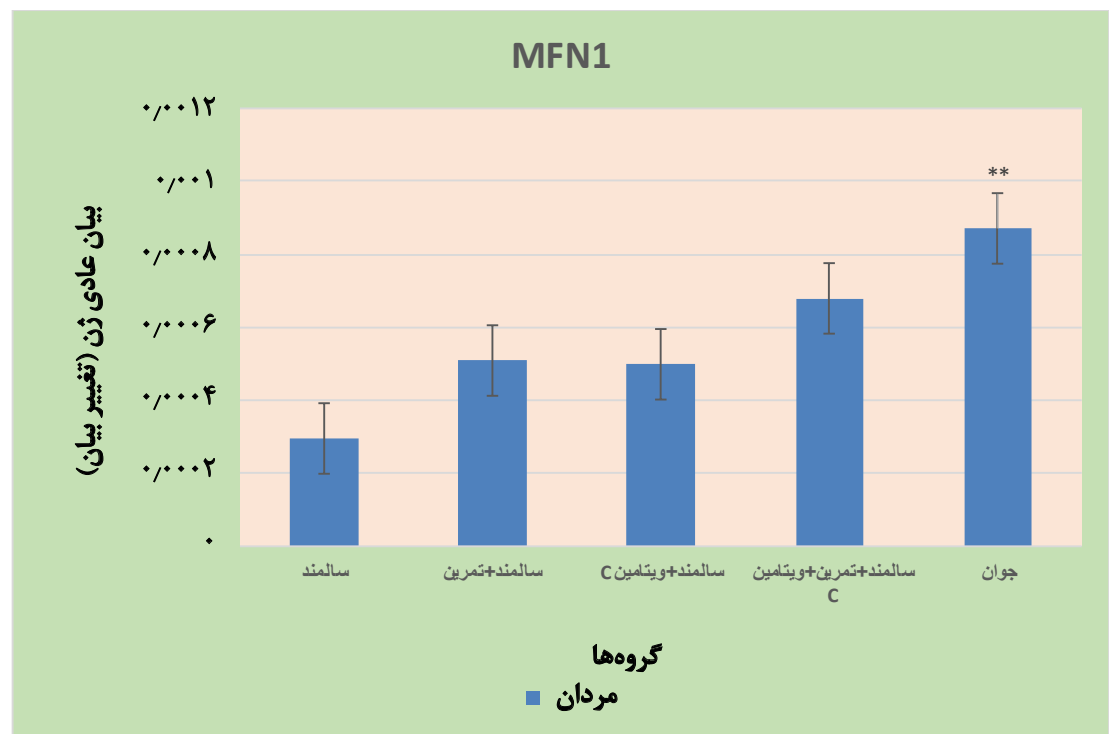

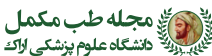

تصوير F. بيان MFn1 در كروهاي مختلف

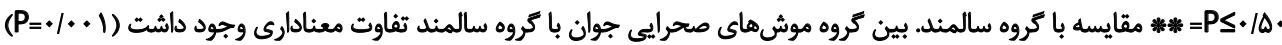




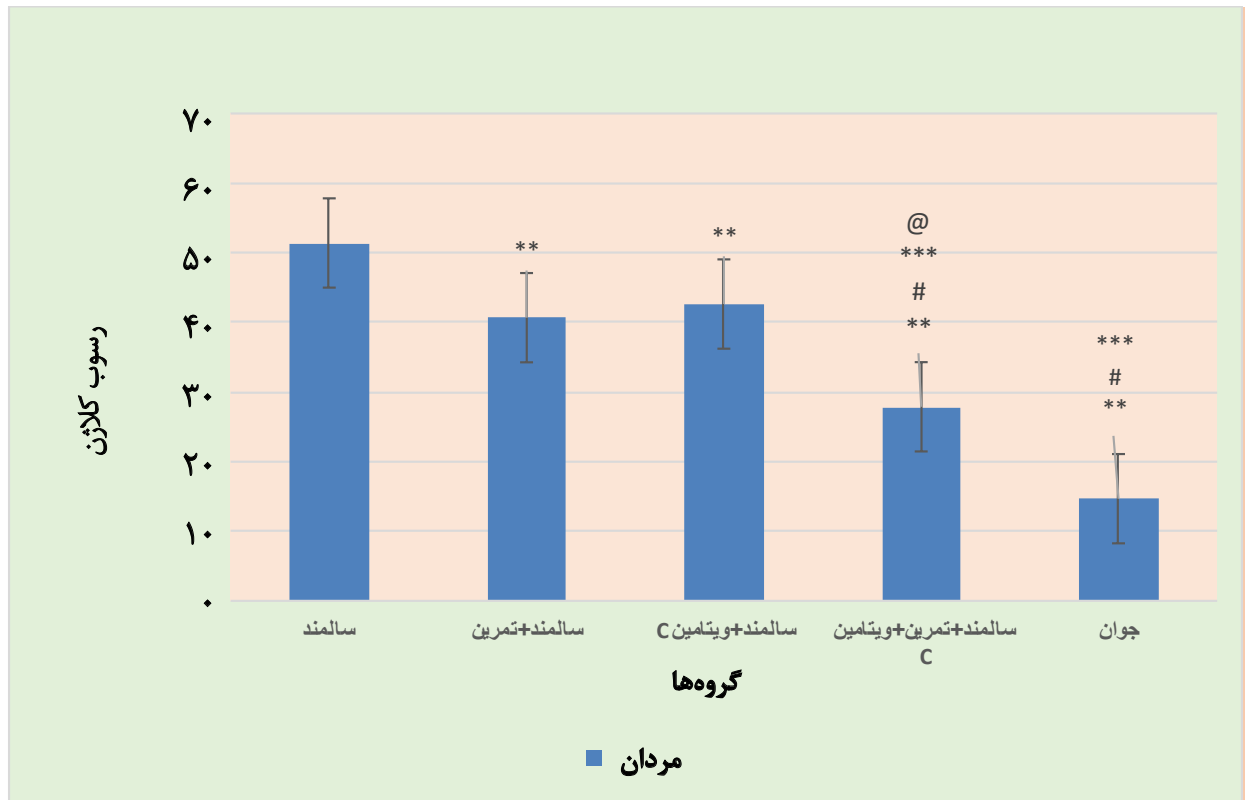

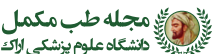

تصوير هـ رسوب كلاثن در كروماي مخثلف

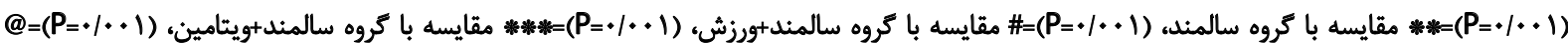

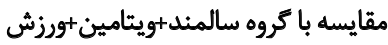

MFn1 در مقايسه با كروه سالمند برخوردار بود (1 .P=).

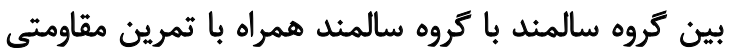
(P=•/MI)

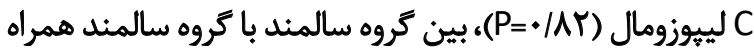

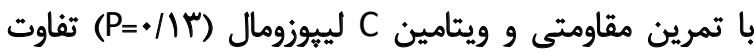
معنادارى از نظر MFn1 مشاهده نشين

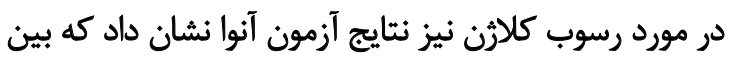

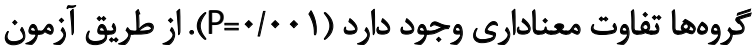

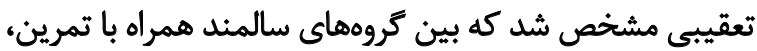

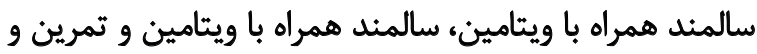

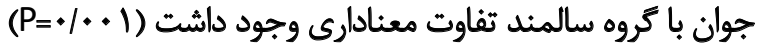

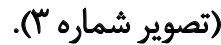

تفاوت بين كروه سالمند همراه با ويتامين و تمرين و كروه

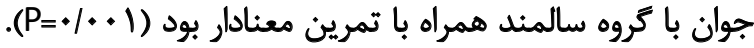

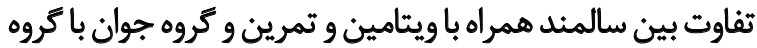

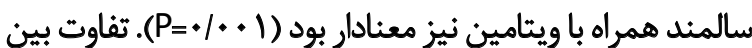

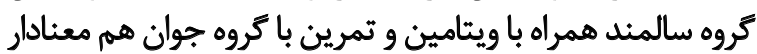

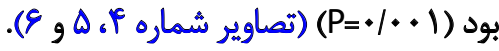

بحث

تحقيق حاضر باهدف اثر بررسى تأثير تمرين ورزشى و مصرف

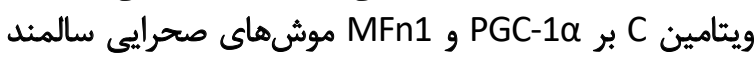
انجام شد. نتايج نشان داد كه سالمندى باعث كاهش معندادار
زا آن قابل مصرف است. ضمناً نكهدارى آن در شيشههاي تيره مناسب است.

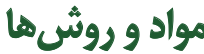

در اين تحقيق، براى بررسى طبيعى بودن توزيع دادهها از آزمون

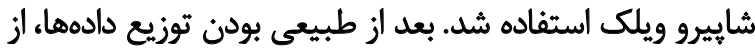

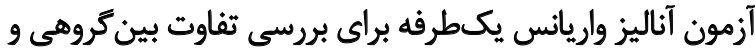

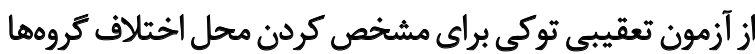

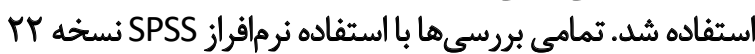

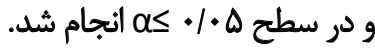

يافتهانها

يافتههاي اين تحقيق از طريق آزمون آنوا نشان داد كه در

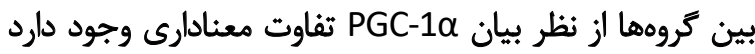

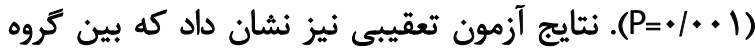

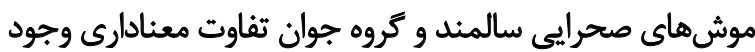

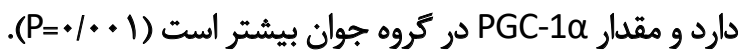

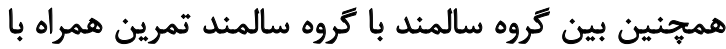

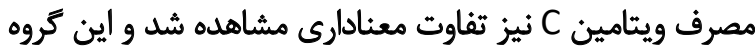

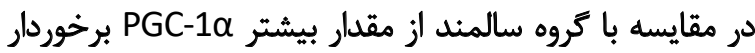

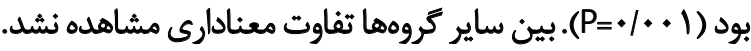
همجنين نتايج آنوا نشان داد كه بين كروهها از نظر

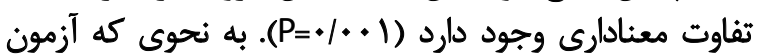
تعقيبى نشان داد كه كروه موش هاي صحرد ائى جوان از مقدار بيشتر 

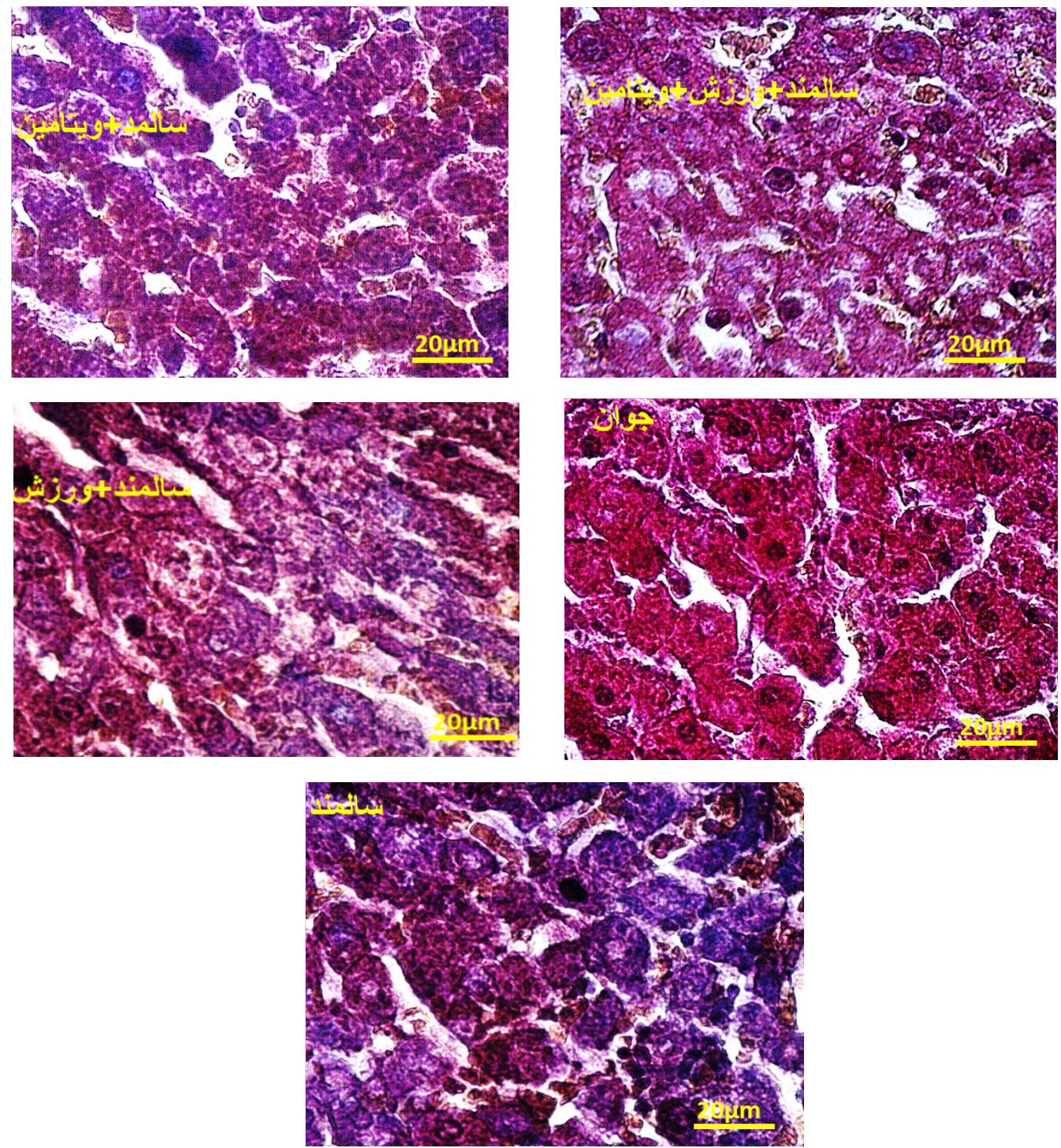

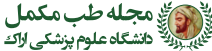

تصوير و رسوب كلاثن

و همكاران كزارش كردند كه تمرين هوازى به همراه مصرف رزوراترول باعث افزايش

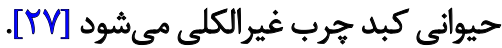

ديكر مطالعات نيز نشان داد كه ورزش تمرين مقاومتى باعث

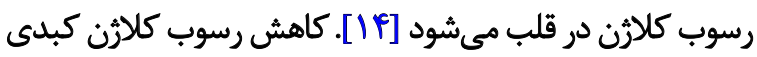

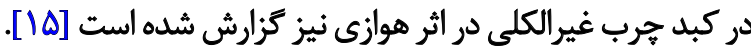
تمرين مقاومتى و مصرف ويتامين از طريق مختلف، مانند

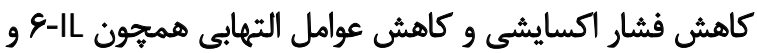

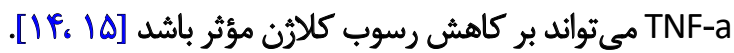

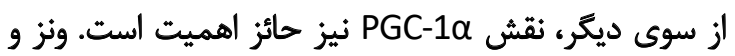

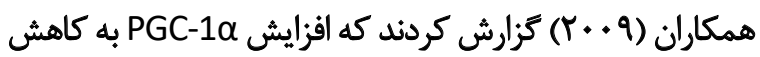

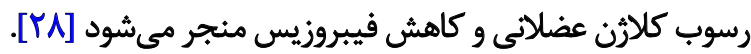

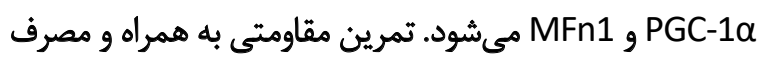

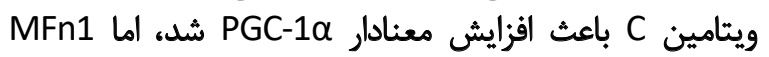
افزايش معنادارى نيافت.

همجنين نتايج نشان داد كه تمرين مقاومتى و مصرف ويتامين

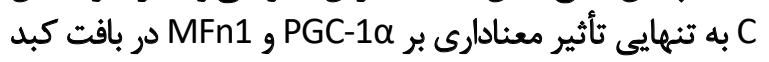

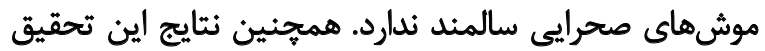

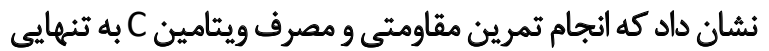

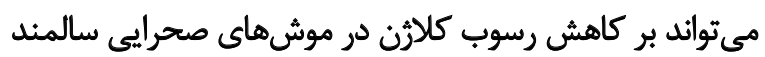

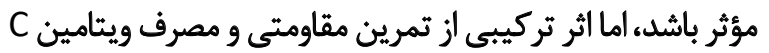

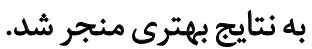

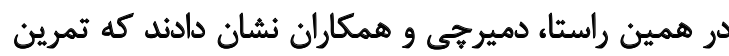

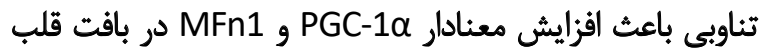
موشهاى صحرايى نر مبتلا به انفاركتوس ميوكارد مى شيود. دلروز 
مؤثر باشد كه در اين تحقيق بررسى نشده است. به عبارت ديكر،

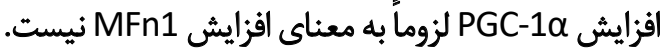

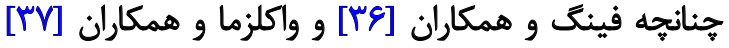

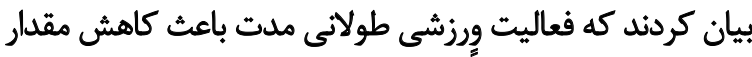

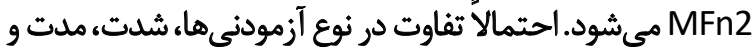

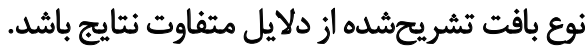

همجينين، بيش بيان PGC-10 و مسيرهاى بيورثز ميتوكندرى

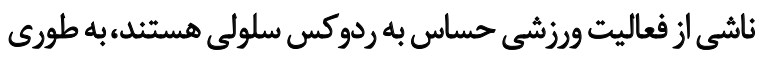

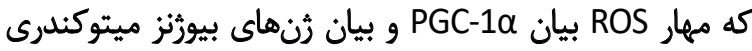

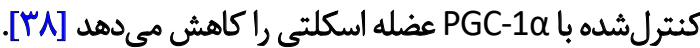

\section{نتيجلهيرى}

درنهايت مىتوان نتيجه كرفت كه تمرين مقاومتى به همراه

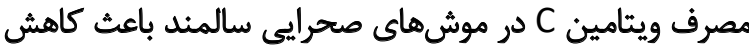

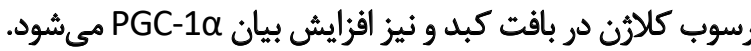

\section{مالاحظات اخلاقى}

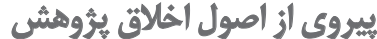

كميته اخلاق ثُروهشكاه تربيت بدنى و علوم ورزشى اين مقاله را تأييد كرده است (كد اخلاق:

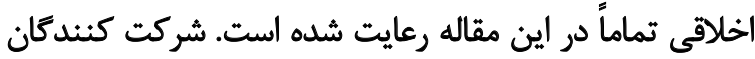

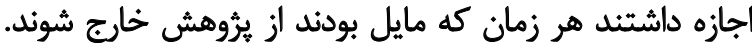

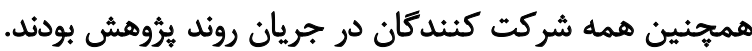
اطلاعات آن ها محرمائه نكَه داشته شد شد.

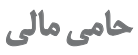

اين مقاله مستخرج از رساله دكترى نويسنده اول در دانشكده

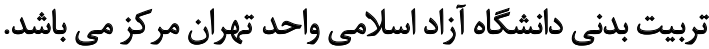

مشاركت نويسند انمان

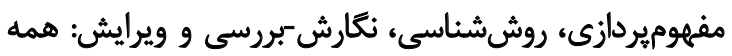

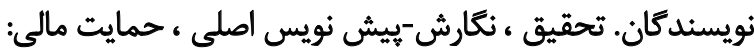

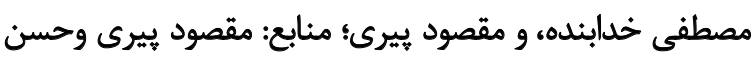

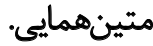

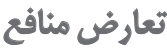

نويسندكان اين مقاله هيجّونه تعارض منافع ندارند.

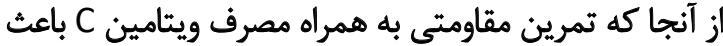

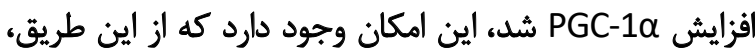

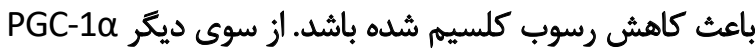

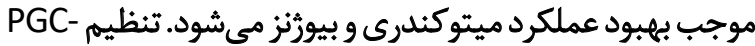

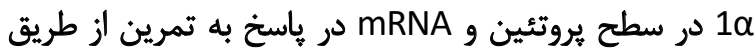

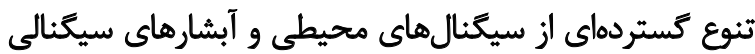

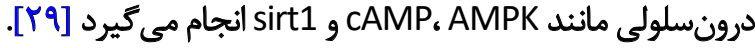

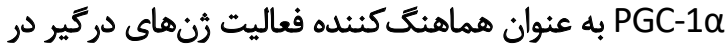

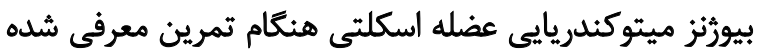

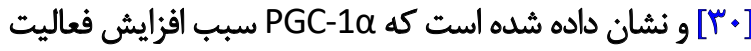

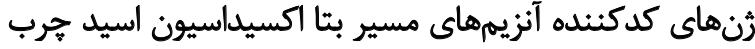

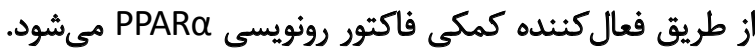

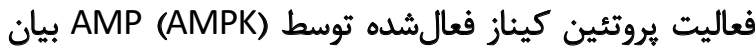

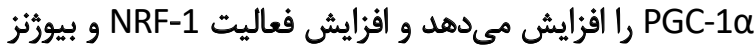

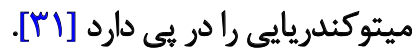
مطالعات اندكى در زمينه آثار تمرينات ورزشى بر دايناميك

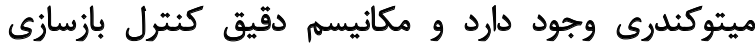

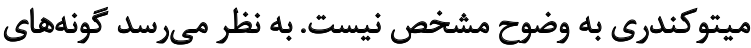

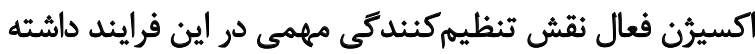

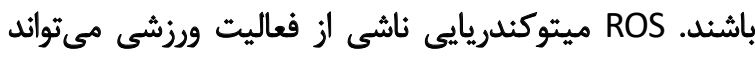

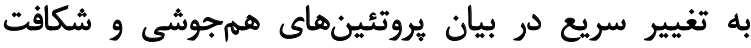
ميتوكندريايى منجر شود [بسان. مطالعات انجامشده نشان داده كه PGC-10 در ساز كارى و ياسخ

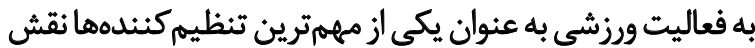

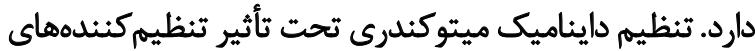

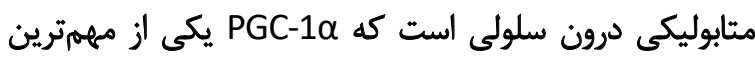

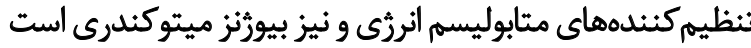

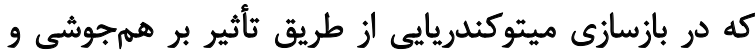

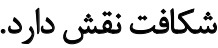

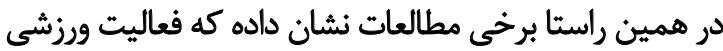
حاد منجر به افزايش بيان mRNA و سطوح يروتئينى در عضله اسكلتى مي لئود كه همراستا با افزايش

[Tr]

مطالعات آزمايشكاهى نشان داده كه بيان MFn1 به طور قابل توجهى در سلولهاي عضلانى فاقد

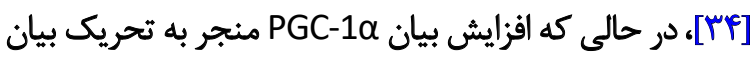

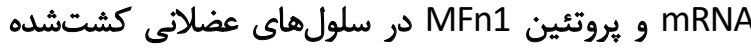

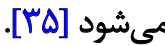

هرجند در تحقيق حاضر افزايش PGC-10 در اثر ورزش و

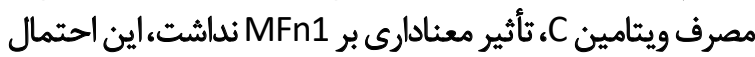

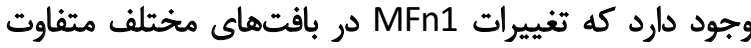

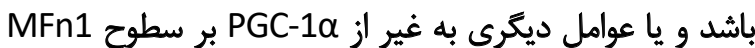




\section{Refrences}

[1] Sonjak V, Jacob KJ, Spendiff S, Vuda M, Perez A, Miguez K, et al. Reduced mitochondrial content, elevated reactive oxygen species, and modulation by denervation in skeletal muscle of prefrail or frail elderly women. The Journals of Gerontology. Series A, Biological Sciences and Medical Sciences. 2019; 74(12):1887-95. [DOI:10.1093/gerona/glz066] [PMID]

[2] Prastowo S, Amin A, Rings F, Held E, Wondim DS, Gad A, et al. Fateful triad of reactive oxygen species, mitochondrial dysfunction and lipid accumulation is associated with expression outline of the AMP-activated protein kinase pathway in bovine blastocysts. Reproduction, Fertility and Development. 2017; 29(5):890-905. [DOI:10.1071/RD15319] [PMID]

[3] Finck BN, Kelly DP. Peroxisome proliferator-activated receptor $\gamma$ coactivator-1 (PGC-1) regulatory cascade in cardiac physiology and disease. Circulation. 2007; 115(19):2540-8. [DOI:10.1161/CIRCULATIONAHA.107.670588] [PMID]

[4] Sebastián D, Palacín M, Zorzano A. Mitochondrial dynamics: Coupling mitochondrial fitness with healthy aging. Trends in Molecular Medicine. 2017; 23(3):201-15. [DOI:10.1016/j.molmed.2017.01.003] [PMID]

[5] Zhang Z, Li TE, Chen M, Xu D, Zhu Y, Hu BY, et al. MFN1-dependent alteration of mitochondrial dynamics drives hepatocellular carcinoma metastasis by glucose metabolic reprogramming. British Journal of Cancer. 2020; 122(2):209-20. [DOI:10.1038/s41416-019-0658-4] [PMID] [PMCID]

[6] Haas RH. Mitochondrial dysfunction in aging and diseases of aging. Biology. 2019; 8(2):48. [DOI:10.3390/biology8020048] [PMID] [PMCID]

[7] Finkel T. Mitochondria, metabolism and aging. The FASEB Journal. 2019; 33(S1):342. [DOI:10.3390/biology8020048]

[8] Ohno T, Hirano S, Rousseau B. Age-associated changes in the expression and deposition of vocal fold collagen and hyaluronan. The Annals of Otology, Rhinology, and Laryngology. 2009; 118(10):735-41. [DOI:10.11 77/000348940911801009] [PMID] [PMCID]

[9] Chung KP, Hsu CL, Fan LC, Huang Z, Bhatia D, Chen YJ, et al. Mitofusins regulate lipid metabolism to mediate the development of lung fibrosis. Nature Communications. 2019; 10(1):3390. [DOI:10.1038/s41467-01911327-1] [PMID] [PMCID]

[10] Islam H, Hood DA, Gurd BJ. Looking beyond PGC-1 $1 \alpha$ : Emerging regulators of exercise-induced skeletal muscle mitochondrial biogenesis and their activation by dietary compounds. Applied Physiology, Nutrition, and Metabolism. 2020; 45(1):11-23. [DOI:10.1139/apnm-2019-0069] [PMID]

[11] Fiuza-Luces $C$, Valenzuela PL, Laine-Menéndez S, Fernández-de la Torre $\mathrm{M}$, Bermejo-Gómez V, Rufián-Vázquez $\mathrm{L}$, et al. Physical exercise and mitochondrial disease: Insights from a mouse model. Frontiers in Neurology. 2019; 10:790. [DOI:10.3389/fneur.2019.00790] [PMID] [PMCID]

[12] Atalay M, Laaksonen DE. Diabetes, oxidative stress and physical exercise. Journal of Sports Science \& Medicine. 2002; 1(1):1-14. [PMID] [PMCID]

[13] Holloszy JO, Booth FW. Biochemical adaptations to endurance exercise in muscle. Annual Review of Physiology. 1976; 38:273-91. [DOI:10.1146/ annurev.ph.38.030176.001421] [PMID]

[14] Alves JP, Nunes RB, Stefani GP, Dal Lago P. Resistance training improves hemodynamic function, collagen deposition and inflammatory profiles: Experimental model of heart failure. PloS One. 2014; 9(10):e110317. [DOI:10.1371/journal.pone.0110317] [PMID] [PMCID]
[15] Linden MA, Sheldon RD, Meers GM, Ortinau LC, Morris EM, Booth $\mathrm{FW}$, et al. Aerobic exercise training in the treatment of non-alcoholic fatty liver disease related fibrosis. The Journal of Physiology. 2016; 594(18):5271-84. [DOI:10.1113/JP272235] [PMID] [PMCID]

[16] Monahan KD, Eskurza I, Seals DR. Ascorbic acid increases cardiovagal baroreflex sensitivity in healthy older men. American Journal of Physiology. Heart and Circulatory Physiology. 2004; 286(6):H2113-7. [DOI:10.1152/ajpheart.01054.2003] [PMID]

[17] Taddei S, Virdis A, Ghiadoni L, Magagna A, Salvetti A. Vitamin C improves endothelium-dependent vasodilation by restoring nitric oxide activity in essential hypertension. Circulation. 1998; 97(22):2222-9. [DOI:10.1161/01.CIR.97.22.2222] [PMID]

[18] Liu L, Zhao SP, Gao M, Zhou QC, Li YL, Xia B. Vitamin C preserves endothelial function in patients with coronary heart disease after a high-fat meal. Clinical Cardiology. 2002; 25(5):219-24. [DOI:10.1002/ clc.4950250505] [PMID] [PMCID]

[19] Sartor Z, Kesey J, Dissanaike S. The effects of intravenous vitamin $C$ on point-of-care glucose monitoring. Journal of Burn Care \& Research. 2015; 36(1):50-6. [DOI:10.1097/BCR.0000000000000142] [PMID]

[20] Rossman MJ, Garten RS, Groot HJ, Reese V, Zhao J, Amann M, et al. Ascorbate infusion increases skeletal muscle fatigue resistance in patients with chronic obstructive pulmonary disease. American Journal of Physiology. Regulatory, Integrative and Comparative Physiology. 2013; 305(10):R1163-70. [DOI:10.1152/ajpregu.00360.2013] [PMID] [PMCID]

[21] Lipka D, Gubernator J, Filipczak N, Barnert S, Süss R, Legut M, et al. Vitamin C-driven epirubicin loading into liposomes. International Journal of Nanomedicine. 2013; 8:3573-85. [DOI:10.2147/IJN. S47745] [PMID] [PMCID]

[22] DePhillipo NN, Aman ZS, Kennedy MI, Begley JP, Moatshe G, LaPrade RF. Efficacy of vitamin C supplementation on collagen synthesis and oxidative stress after musculoskeletal injuries: A systematic review. Orthopaedic Journal of Sports Medicine. 2018, 6(10):2325967118804544 [DOI:10.1177/2325967118804544] [PMID] [PMCID]

[23] Soltanian Z, Vanaky B, ramezani fard N, Shakeri N, Shams Z, Fakhar Rad F. [Effect of eight weeks resistance training on gene expression of TNF-A and IL10 in the heart of type ii diabetic male rats (Persian)]. Journal of Shahid Sadoughi University of Medical Sciences. 2019; 27(6):1656-67. [DOI:10.18502/ssu.v27i6.1600]

[24] Khalili A, Alipour S, Fathalipour M, Purkhosrow A, Mashghoolozekr E, Bayat G, et al. Liposomal and non-liposomal formulations of vitamin C: Comparison of the antihypertensive and vascular modifying activity in renovascular hypertensive rats. Iranian Journal of Medical Sciences. 2020; 45(1):41-9. [PMID] [PMCID] [DOI:10.18502/ssu. v27i6.1600]

[25] Thirupathi A, da Silva Pieri BL, Queiroz JAMP, Rodrigues MS, de Bem Silveira G, de Souza DR, et al. Strength training and aerobic exercise alter mitochondrial parameters in brown adipose tissue and equally reduce body adiposity in aged rats. Journal of Physiology and Biochemistry. 2019; 75(1):101-8. [DOI:10.1007/s13105-019-00663-x] [PMID]

[26] Scheffer DL, Silva LA, Tromm CB, da Rosa GL, Silveira PC, de Souza $\mathrm{CT}$, et al. Impact of different resistance training protocols on muscular oxidative stress parameters. Applied Physiology, Nutrition, and Metabolism. 2012; 37(6):1239-46. [DOI:10.1139/h2012-115] [PMID]

[27] Delroz H, Abdi A, Barari A, Farzanegi P. [The effect of eight weeks of aerobic training combined with resveratrol on MFn1 and MFn2 
expression in cardiac myocytes in a Non-alcoholic fatty liver animal model (Persian)]. Complementary Medicine Journal. 2020; 9(4):3878-89. [DOI:10.32598/cmja.9.3.627.3]

[28] Wenz T, Rossi SG, Rotundo RL, Spiegelman BM, Moraes CT. Increased muscle PGC- $1 \alpha$ expression protects from sarcopenia and metabolic disease during aging. Proceedings of the National Academy of Sciences of the United States of America. 2009; 106(48):20405-10. [DOI:10.1073/pnas.0911570106] [PMID] [PMCID]

[29] Puigserver P, Rhee J, Lin J, Wu Z, Yoon JC, Zhang CY, et al. Cytokine stimulation of energy expenditure through p38 MAP kinase activation of PPARY coactivator-1. Molecular Cell. 2001; 8(5):971-82. [DOI:10.1016/S1097-2765(01)00390-2]

[30] Hood DA, Irrcher I, Ljubicic V, Joseph AM. Coordination of metabolic plasticity in skeletal muscle. The Journal of Experimental Biology. 2006; 209(Pt 12):2265-75. [DOI:10.1242/jeb.02182] [PMID]

[31] Rodgers JT, Lerin C, Haas W, Gygi SP, Spiegelman BM, Puigserver P. Nutrient control of glucose homeostasis through a complex of PGC1alpha and SIRT1. Nature. 2005; 434(7029):113-8. [DOI:10.1038/ nature03354] [PMID]

[32] Yu T, Robotham JL, Yoon Y. Increased production of reactive oxygen species in hyperglycemic conditions requires dynamic change of mitochondrial morphology. Proceedings of the National Academy of Sciences of the United States of America. 2006; 103(8):2653-8. [DOI:10.1073/pnas.0511154103] [PMID] [PMCID]

[33] Ding $H$, Jiang N, Liu H, Liu X, Liu D, Zhao F, et al. Response of mitochondrial fusion and fission protein gene expression to exercise in rat skeletal muscle. Biochimica et Biophysica Acta (BBA) - General Subjects. 2010; 1800(3):250-6. [DOI:10.1016/j.bbagen.2009.08.007] [PMID]

[34] St-Pierre J, Drori S, Uldry M, Silvaggi JM, Rhee J, Jäger S, et al. Suppression of reactive oxygen species and neurodegeneration by the PGC-1 transcriptional coactivators. Cell. 2006; 127(2):397-408. [DOI:10.1016/j.cell.2006.09.024] [PMID]

[35] Liesa M, Borda-d'Agua B, Medina-Gómez G, Lelliott CJ, Paz JC, Rojo $M$, et al. Mitochondrial fusion is increased by the nuclear coactivator PGC-1ß. PloS One. 2008; 3(10):e3613. [DOI:10.1371/journal. pone.0003613] [PMID] [PMCID]

[36] Feng H, Kang C, Dickman JR, Koenig R, Awoyinka I, Zhang Y, et al. Training-induced mitochondrial adaptation: Role of peroxisome proliferator-activated receptor $\gamma$ coactivator-1 $\alpha$, nuclear factor-kB and $\beta$-blockade. Experimental Physiology. 2013; 98(3):784-95. [DOI:10.1113/expphysiol.2012.069286] [PMID]

[37] Wyckelsma VL, Levinger I, McKenna MJ, Formosa LE, Ryan MT, Petersen AC, et al. Preservation of skeletal muscle mitochondrial content in older adults: Relationship between mitochondria, fibre type and high-intensity exercise training. The Journal of Physiology. 2017; 595(11):3345-59. [DOI:10.1113/JP273950] [PMID] [PMCID]

[38] Huh JY, Mougios V, Kabasakalis A, Fatouros I, Siopi A, Douroudos II, et al. Exercise-induced irisin secretion is independent of age or fitness level and increased irisin may directly modulate muscle metabolism through AMPK activation. The Journal of Clinical Endocrinology \& Metabolism. 2014; 99(11):E2154-61. [DOI:10.1210/jc.20141437] [PMID] 
This Page Intentionally Left Blank 